\title{
ESTRATÉGIAS PARA A SÍNTESE DO ÁCIDO LISÉRGICO
}

\author{
Tamiris R. C. Silva ${ }^{a}$ e Cristiano Raminelli*,a, (i) \\ aDepartamento de Química, Instituto de Ciências Ambientais, Químicas e Farmacêuticas, Universidade Federal de São Paulo, \\ 09972-270 Diadema - SP, Brasil
}

Recebido em 05/01/2021; aceito em 04/03/2021; publicado na web em 31/03/2021

\begin{abstract}
STRATEGIES FOR THE SYNTHESIS OF LYSERGIC ACID. (+)-Lysergic acid [(+)-1] is a precursor of several substances with well-established pharmacological properties, including some drugs approved and commercialized around the world. Thus, the importance of (+)-1 as a synthetic target becomes undoubted and various strategies for the synthesis of its tetracyclic core have been reported in the literature. Therefore, in this review article we will address in chronological order the total and formal syntheses of lysergic acid (1), separating them into racemic and chiral/asymmetric syntheses. Until now, there are 24 syntheses described in the literature, namely, 11 total and 13 formal syntheses. Considering all the syntheses accomplished, 15 were planned to produce $( \pm)$-lysergic acid $[( \pm)-\mathbf{1}]$ and 9 presented routes to eventually provide (+)-lysergic acid $[(+)-\mathbf{1}]$. A significant evolution regarding approaches and efficiency may be observed since the first synthesis of ( \pm )-1 until the last asymmetric synthesis of $(+)-\mathbf{1}$.
\end{abstract}

Keywords: total synthesis; formal synthesis; ergoline alkaloids; lysergic acid.

\section{INTRODUÇÃO}

$\mathrm{O}(+)$-ácido lisérgico [(+)-1] é um representante dos alcaloides ergolínicos, isolados de fungos do gênero Claviceps, bem como de fungos de outros gêneros e plantas superiores..$^{1-3}$ Os alcaloides dessa classe são derivados biossintéticos do aminoácido L-triptofano e podem ser divididos em três subclasses: (ergo)clavinas; ergoamidas e ergopeptinas. ${ }^{1-3}$ Mesmo existindo três subclasses, a maioria dos alcaloides ergolínicos possuem um núcleo tetracíclico, constituído por um sistema indólico (anéis A e B) derivado do L-triptofano, que por prenilação com difosfato de dimetilalila (DMAPP), seguida por sequência de transformações envolvendo ciclizações levam à formação dos anéis C e $\mathrm{D}^{1-3}$ (Figura 1).

Na maioria dos alcaloides ergolínicos, o núcleo tetracíclico é metilado em N6, substituído em C8 e possui uma ligação dupla na

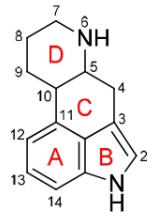

núcleo ergolínico

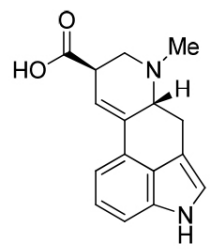

$(+)$-ácido lisérgico $[(+)-\mathbf{1}]$

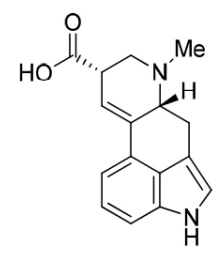

(+)-ácido isolisérgico

Figura 1. Núcleo ergolínico e estruturas do (+)-ácido lisérgico $[(+)-1]$ e do (+)-ácido isolisérgico

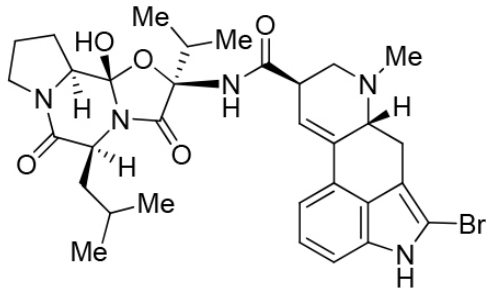

bromocriptina

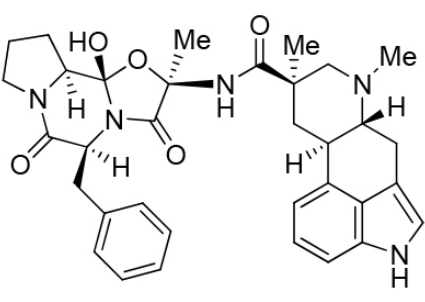

di-hidroergotamina posição C8/C9 ( $\Delta^{8,9}$-ergolenos) ou C9/C10 ( $\Delta^{9,10}$-ergolenos), com centros estereogênicos em $\mathrm{C} 5 / \mathrm{C} 10$ ou $\mathrm{C} 5 / \mathrm{C} 8$, respectivamente. A posição 5 sempre terá configuração $R$ e, geralmente, $\Delta^{8,9}$-ergolenos apresentarão o hidrogênio em C10 trans em relação ao hidrogênio em C5. Adicionalmente, o centro estereogênico em C8 para $\Delta^{9,10}$ ergolenos dará origem a dois epímeros, que exemplificamos através do (+)-ácido lisérgico [(+)-1], que possui o centro estereogênico da posição 8 com configuração $R$, e do (+)-ácido isolisérgico, com o centro estereogênico da posição 8 apresentando configuração $S{ }^{4}$

Os alcaloides ergolínicos podem atuar como agonistas ou antagonistas de receptores dopaminérgicos, serotoninérgicos e adrenérgicos, apresentando um amplo espectro de propriedades farmacológicas, que tornam tais compostos potenciais precursores de novos fármacos. ${ }^{1,3}$ Nesse contexto, destacamos os fármacos bromocriptina usado no tratamento do mal de Parkinson e de hiperprolactinemia, ${ }^{2,5}$ di-hidroergotamina empregado no tratamento de ataques de enxaqueca aguda ${ }^{2,5}$ e nicergolina usado no tratamento de demência, isquemia transitória e trombose cerebral ${ }^{2,5}$ (Figura 2).

Considerando o $(+)$-ácido lisérgico $[(+)-1]$ como precursor para diversas substâncias com propriedades farmacológicas de interesse, a sua importância como alvo sintético torna-se indiscutível. ${ }^{1-3}$ Neste cenário, atualmente, diversas estratégias para a síntese de alcaloides ergolínicos estão descritas na literatura. ${ }^{1,6-8}$ Portanto, neste artigo de revisão abordaremos as sínteses formais e totais do ácido lisérgico, separando-as em sínteses racêmicas e quirais/assimétricas, por ordem cronológica. Para definirmos quais estruturas seriam mostradas nos

Figura 2. Estruturas de fármacos que contém o núcleo ergolínico<smiles>CO[C@]12C[C@H](COC(=O)c3cncc(Br)c3)CN(C)[C@H]1Cc1cn(C)c3cccc2c13</smiles>

nicergolina

*e-mail: raminelli@unifesp.br 
esquemas, decidimos apresentar as formações dos anéis A, B, C e D do esqueleto ergolínico (com poucas exceções). Tais transformações compreenderam algumas das reações chaves consideradas pelos autores dos artigos originais, as quais foram destacadas nos esquemas. Vale mencionar que até o presente momento existem 24 sínteses descritas na literatura, ${ }^{9-32} 11$ totais e 13 formais. Considerando todas as sínteses realizadas, 15 foram planejadas para produzir ( \pm )-ácido lisérgico $[( \pm)-\mathbf{1}]^{9-23}$ e 9 apresentaram rotas para eventualmente fornecerem $(+)$-ácido lisérgico $[(+)-1] .{ }^{24-32}$

\section{SÍNTESES RACÊMICAS}

A primeira síntese do $( \pm)$-ácido lisérgico [( \pm -1] foi divulgada através de uma comunicação realizada por Woodward e colaboradores em 1954, ${ }^{9}$ que publicaram um artigo completo em 1956, apresentando um detalhamento sobre a síntese. ${ }^{10}$ Woodward e colaboradores obtiveram o $( \pm)$-ácido lisérgico $[( \pm)-1]$, em um período que antecedeu o emprego da técnica de RMN, importante ferramenta para a elucidação estrutural de substâncias orgânicas. Ao longo da síntese desenvolvida, os compostos obtidos foram identificados e caracterizados por comparação de propriedades físicas e cromatográficas, bem como através de suas análises elementares. Adicionalmente, suas estruturas foram propostas por meio de técnicas de espectroscopia de absorção no ultravioleta e na região do infravermelho. Nesse contexto, fica evidente que poucas informações sobre as estruturas tridimensionais das moléculas estavam disponíveis. A rota sintética simplificada para $( \pm)-\mathbf{1}$, contendo o material de partida, os principais intermediários e as reações chaves (destacadas), está delineada no Esquema 1.

A primeira síntese total do $( \pm)$-ácido lisérgico $[( \pm)-1]$ foi iniciada pela transformação do derivado indólico 2 no derivado indolínico protegido 3, que por reação de acilação de Friedel-Crafts resultou na cetona tricíclica 5, que ficou conhecida como cetona de Kornfeld. Após algumas transformações de grupos funcionais, o composto dicarbonílico 6 foi obtido e por condensação aldólica intramolecular resultou no intermediário $\mathbf{8}$, que apresenta o núcleo ergolínico. $\mathrm{O}$ composto 8 foi convertido no ( \pm )-ácido lisérgico [( \pm$)$-1 $]$ após 6 etapas envolvendo reações de proteção e desproteção, hidrólise alcalina e desidrogenação catalítica. A síntese total desenvolvida por Woodward e colaboradores foi concluída após 15 etapas, com rendimento global de $0,8 \% \%^{9,10}$ (Esquema 1).
Em 1969, Julia e colaboradores empregaram uma abordagem alternativa para a construção do núcleo ergolínico, envolvendo reação de ciclização intramolecular via química de benzino, que resultou na formação do composto tetracíclico ( \pm )-14 ${ }^{11}$ (Esquema 2).

A primeira síntese formal do $( \pm)$-ácido lisérgico $[( \pm)-1]$ teve início pela condensação dos compostos 6-metilnicotinato de metila (9) e 5-bromoindolin-2,3-diona (10). Embora a síntese formal realizada pelo grupo de Julia tenha sido concluída em sete etapas reacionais, seu rendimento global não pode ser calculado pela ausência dos valores de rendimentos para as reações apresentadas, com exceção da reação chave que resultou no derivado ergolínico ( \pm )-14 em 15\% de rendimento (após purificação cromatográfica), através de uma ciclização intramolecular via química de benzino, entre a porção nicotínica e a porção indolínica do intermediário $( \pm)$-12, seguida de uma migração de ligação dupla. ${ }^{11}$ Vale mencionar que os autores compararam o composto $( \pm)-\mathbf{1 4}$, com uma amostra de referência preparada a partir do D-lisergato de metila, bem como com uma amostra correspondente ao composto $( \pm)-\mathbf{1 4}$, fornecida pelo grupo de Woodward, ${ }^{9,10}$ sintetizada para estudar a desidrogenação do esqueleto ergolínico, durante a síntese do ( \pm -ácido lisérgico $[( \pm)-1]^{10}($ Esquema 2$)$.

Quase uma década depois, em 1976, outra síntese formal para o $( \pm)$-ácido lisérgico [( \pm -1] foi divulgada pelo grupo de Ramage, ${ }^{12}$ que apresentou uma estratégia baseada no mecanismo de conversão do (+)-ácido lisérgico [(+)-1] e do (+)-ácido isolisérgico para o ( \pm )-ácido lisérgico [( \pm -1 1], descrita anteriormente por Woodward. ${ }^{10}$ Levando em conta que tal conversão possivelmente acontecia devido a abertura do anel D, Ramage e colaboradores decidiram construir o intermediário 19, que através de uma ciclização espontânea, resultou no núcleo ergolínico de interesse. Os resultados obtidos pelo grupo de Ramage, envolvendo a síntese formal do ( \pm )-ácido lisérgico [( \pm$)-\mathbf{1}]$, foram publicados através de um artigo completo em $1981^{13}$ (Esquema 3 ).

A síntese formal do ( \pm )-ácido lisérgico $[( \pm)-1]$ foi iniciada pela reação de Wittig entre a fosforana 15 e o aldeído 16 (sintetizado em duas etapas), para formar o diéster 18 com configuração $E$. O composto $\mathbf{1 8}$ foi convertido em ácido carboxílico, que após uma degradação de Curtius levou à formação da amina 19. Segundo a literatura, ${ }^{13,33}$ a $N$-alquilação da amina 19 facilitaria a ciclização espontânea. Portanto, o composto 19 foi submetido à reação de Eschweiler-Clarke, com formaldeído e ácido fórmico, levando presumivelmente à formação da amina secundária $\mathbf{2 0}$, como
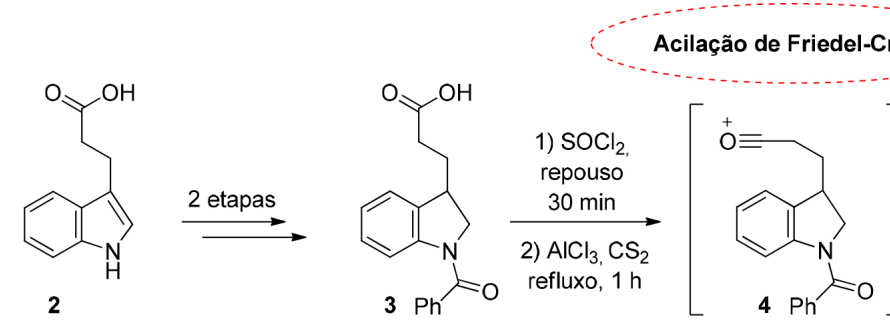

$3 \mathrm{Ph}^{\prime}$

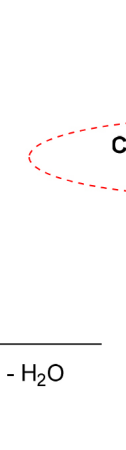

( \pm )-ácido lisérgico $[( \pm)-1]$
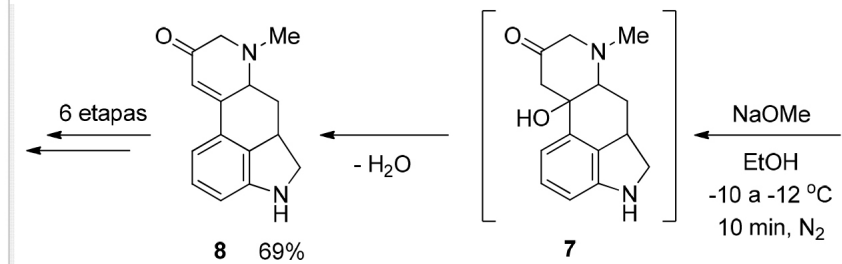

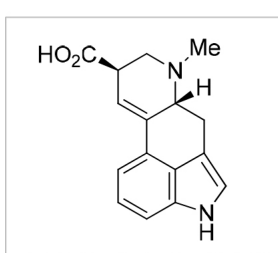

$869 \%$
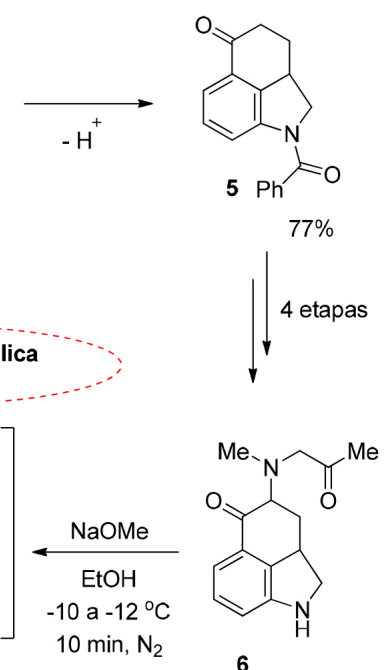

6

Esquema 1. Primeira síntese total do (土)-ácido lisérgico [(土)-1] realizada por Woodward e colaboradores na década de 1950 
<smiles>COC(=O)c1ccc(C)nc1</smiles>

9<smiles>O=C1Nc2ccc(Br)cc2C1=O</smiles>

10<smiles>COC(=O)c1ccc(C=C2C(=O)Nc3ccc(Br)cc32)nc1</smiles>

$(Z)-11$ e $(E)-11$

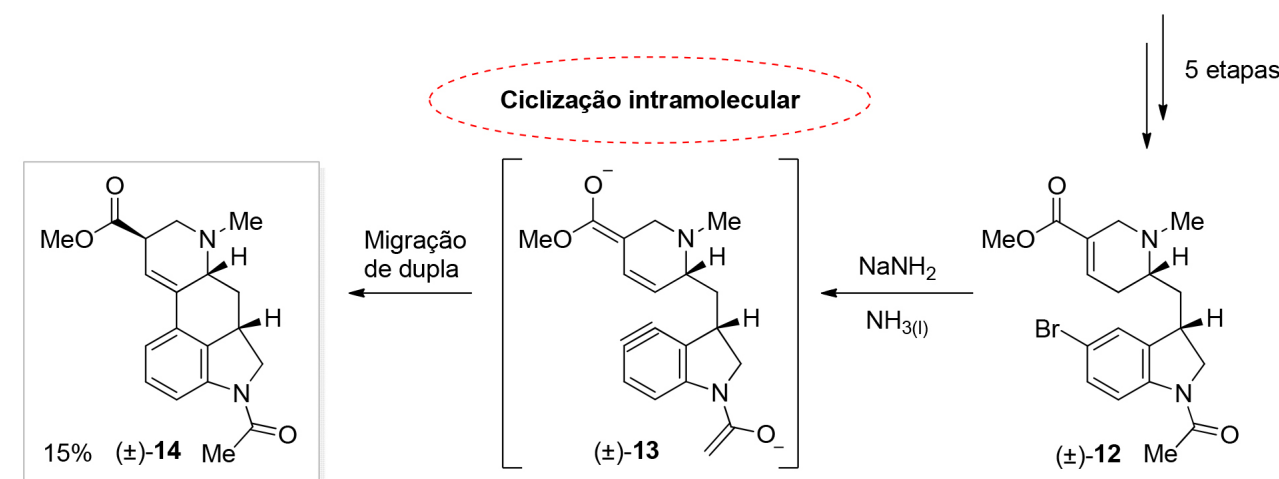

Esquema 2. Primeira síntese formal do ( \pm )-ácido lisérgico [( \pm )-1] publicada por Julia e colaboradores em 1969

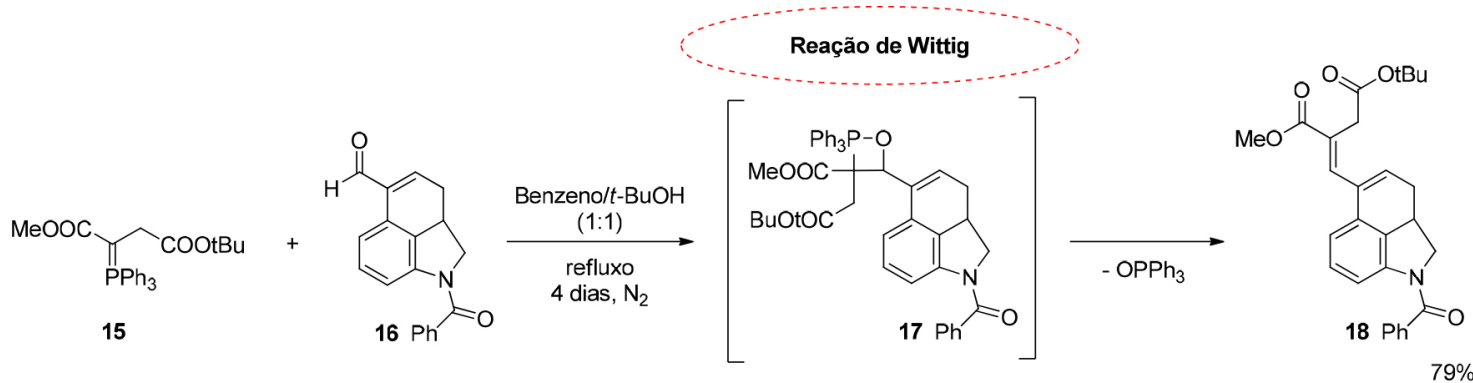<smiles>COC(=O)[C@@H]1C=C2c3cccc4c3[C@@H](CN4)[C@H](C)[C@H]2CN1C</smiles>

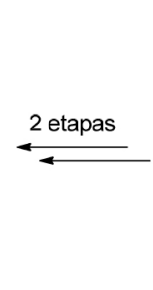<smiles>COC(=O)[C@H]1C=C2c3cccc4c3C(C[C@H]2N(C)C1)CN4C(=O)c1ccccc1</smiles><smiles>COC(=O)C1=C[C@@H]2c3cccc4c3[C@@H](C[C@H]2N(C)C1)[C@H]4N</smiles>

$( \pm)-21 \mathrm{Ph}^{\prime}=0$

$62 \%$

(para a mistura de isômeros na proporção 9:3:2)

Esquema 3. Síntese formal do ( \pm )-ácido lisérgico [( \pm -1] realizada por Ramage e colaboradores entre as décadas 70 e 80

intermediário da reação chave de formação do núcleo ergolínico. Essa reação teve como produtos três isômeros, sendo dois epímeros (( \pm -22 e 8-epi-22) e um isômero constitucional [( \pm )-21] na proporção de 9:3:2, respectivamente. O composto $( \pm)-21$ não pode ser isolado na forma pura, devido a uma contaminação com 8-epi-22, resultante de uma migração de ligação dupla promovida pela sílica gel durante a purificação por cromatografia. A mistura dos epímeros $( \pm)-\mathbf{2 2}$ e 8-epi-22 foi submetida a transformações de grupos funcionais fornecendo os produtos ( \pm -23 e 8-epi-23 na proporção de 5:2, respectivamente. A rota descrita por Ramage e colaboradores além de produzir os compostos ( \pm )-23 e 8-epi-23, que foram previamente sintetizados pelo grupo de Woodward,, 910 embora não apresentados no Esquema 1, fornece mais informações a respeito das estruturas das substâncias, por ter utilizado técnicas como RMN e CLAE, não disponíveis na primeira metade da década de 50. A síntese formal desenvolvida por Ramage e colaboradores foi finalizada após 11 etapas, com rendimento global de $14,0 \%$, considerando o precursor do composto 16, ${ }^{10}$ como material de partida ${ }^{12,13}$ (Esquema 3). 
Em 1981, Oppolzer e colaboradores empregaram uma abordagem sem precedentes na síntese total do ( \pm )-ácido lisérgico [( \pm )-1] a qual manteve intacto o núcleo indólico, sem a necessidade de etapas de hidrogenação e desidrogenação, apresentando como reação chave uma imino Diels-Alder, que permitiu a formação dos anéis C e D em uma única etapa ${ }^{14}$ (Esquema 4).

A síntese total do $( \pm)$-ácido lisérgico $[( \pm)$-1] foi iniciada transformando 4-hidróxi-metil-1-tosilindol (24), por interconversões de grupos funcionais, envolvendo reação de Wittig para inserção do sistema bicíclico, remoção do grupo tosila e reação de Mannich, nos diastereoisômeros $(Z)-\mathbf{2 5}$ e $(E)$-25 na proporção de 3:2, respectivamente. Na etapa chave os compostos $(Z)-25$ e $(E)$-25 foram convertidos através dos intermediários $(Z)$-26 e $(E)$-26, que não puderam ser isolados, nos epímeros ( \pm )-27 e 10-epi-27, que foram obtidos em $67 \%$ de rendimento na proporção de 3:2, respectivamente. Os compostos ( \pm -27 e 10epi-27 foram convertidos no ( \pm )-ácido lisérgico $[( \pm)-\mathbf{1}]$ em $33 \%$ de rendimento, após três etapas reacionais (sem isolamento). A síntese total de Oppolzer e colaboradores foi concluída em 11 etapas, com rendimento global de 3,9\% ${ }^{14}$ (Esquema 4).

Na década de 80, o interesse pela síntese do ácido lisérgico teve um aumento considerável e, em decorrência disso, o número de artigos publicados foi bem maior do que na década anterior. Nesse contexto, em 1982, o grupo de Ninomiya reportou uma síntese formal para o ( \pm )-ácido lisérgico $[( \pm)-1]$, utilizando uma estratégia que envolveu na etapa chave uma fotociclização de enamida intramolecular para a formação do núcleo ergolínico, ${ }^{15}$ a qual foi otimizada e detalhada através de um artigo completo publicado em $1985^{16}$ (Esquema 5).

A síntese formal do $( \pm)$-ácido lisérgico $[( \pm)-1]$ foi iniciada com a cetona tricíclica $\mathbf{2 8}$, que possui o nitrogênio indólico protegido, da qual se obtém a enamida $\mathbf{3 0}$, que foi submetida à reação chave fazendo uso de excesso de boroidreto de sódio em uma solução de benzeno/ metanol (5:1), irradiada por uma lâmpada de mercúrio de $300 \mathrm{~W}$ a 4-10 ${ }^{\circ} \mathrm{C}$, sofrendo uma ciclização conrotatória envolvendo 6 elétrons $\pi$, que resultou na formação dos intermediários ( \pm -32a, $( \pm)-32 \mathbf{b}$ e $( \pm)-32 \mathbf{c}$. O estereoisômero $( \pm)-\mathbf{3 2 c}$ (produto majoritário) foi submetido a uma sequência de transformações que levou à formação de uma mistura de cis-glicóis 33a e 33b na proporção de 3:2. Os compostos 33a e 33b foram convertidos em três etapas nos intermediários ( \pm )-22 e 8-epi22 na proporção de 3:1, que resultaram em duas etapas nos ésteres metílicos ( \pm )-34 e 8-epi-34 na proporção de 3:2, respectivamente. A síntese formal desenvolvida Ninomiya e colaboradores foi concluída em 12 etapas, com rendimento global de 2,2\% ${ }^{15,16}$ (Esquema 5).

Em 1983, o grupo de Rebek Jr. divulgou a síntese formal do $( \pm)$-ácido lisérgico $[( \pm)-\mathbf{1}]$, empregando como material de partida o aminoácido L-triptofano (35), visando obter o composto [(+)-1] (enantiomericamente puro), através de uma síntese diastereosseletiva. ${ }^{17}$ Um ano mais tarde, a síntese formal do $( \pm)$-ácido lisérgico $[( \pm)-1]$ foi publicada pelo mesmo grupo de maneira detalhada, contendo outros dois alcaloides ergolínicos, obtidos a partir de um intermediário em comum $^{18}$ (Esquema 6).

Inicialmente, L-triptofano (35) foi reduzido e dibenzoilado, fornecendo o intermediário (-)-36. O composto (-)-36 foi tratado com $\mathrm{Ac}_{2} \mathrm{O}$ e, posteriormente, com $\mathrm{AlCl}_{3}$, que promoveu uma acilação de Friedel-Crafts intramolecular estereosseletiva, resultando no intermediário (-)-37. Os carbonos necessários para a formação do anel D foram introduzidos através de uma reação de Reformatsky, empregando $\alpha$-(bromometil)acrilato de etila, que originou a lactona (+)-40. Após algumas transformações de grupos funcionais, a lactona (+)-41 foi obtida, sendo que a partir dela a síntese foi continuada de maneira racêmica, resultando no final em uma mistura de epímeros previamente sintetizada por outro grupo. ${ }^{16}$ Os autores do artigo não explicaram por que a síntese foi finalizada de maneira racêmica. No entanto, vale mencionar que a síntese foi conduzida com substâncias enantiomericamente puras até o intermediário (+)-41 e de maneira racêmica do início até os compostos ( \pm )-34 e 8-epi-34. A síntese formal desenvolvida por Rebek Jr. e colaboradores foi concluída em 11 etapas, com rendimento global de 3,0\% ${ }^{17,18}$ (Esquema 6).

Kurihara e colaboradores realizaram uma síntese formal para o

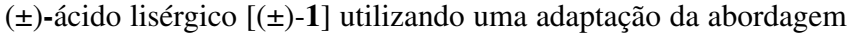
adotada pelo grupo de Ramage (Esquema 3), ${ }^{12,13}$ divulgada através de uma comunicação em $1986^{19} \mathrm{e}$, posteriormente, por meio de um artigo completo em $1987^{20}$ (Esquema 7).

O material de partida escolhido para a síntese foi a cetona $\mathbf{5}$, que pode ser convertida no aldeído 16 utilizado por Ramage. A conversão de 5 em 16 foi descrita pelo grupo de Kurihara de duas maneiras, uma delas delineada na comunicação de 1986 (Esquema 7 - caminho A) ${ }^{19}$ e a outra apresentada no artigo completo de 1987 (Esquema 7 caminho B). ${ }^{20} \mathrm{O}$ aldeído $\mathbf{1 6}$ foi adicionado a uma mistura contendo o composto 45 e LDA, sofrendo uma adição aldólica que resultou na mistura diastereoisomérica dos álcoois $47 \mathrm{em}$ rendimento

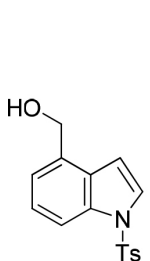

24

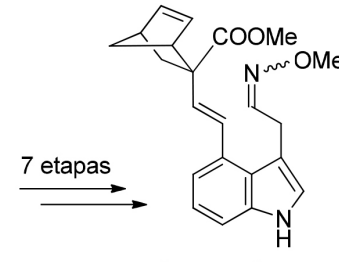

$(Z)-25$ e $(E)-25(3: 2)$ (adição via bomba de seringa)
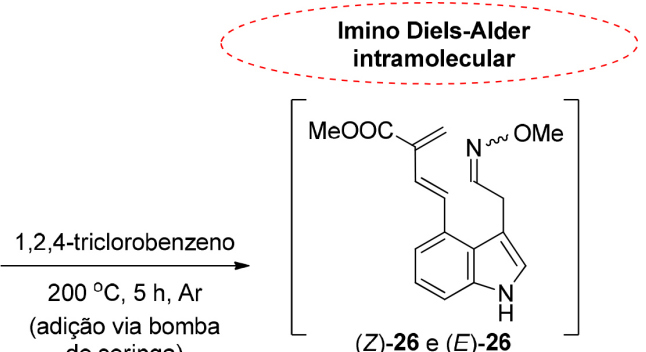

$(Z)-26$ e $(E)-26$

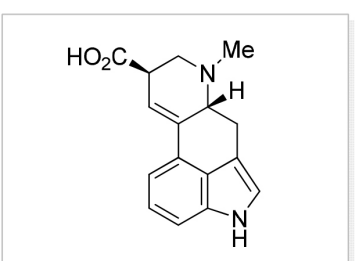

$( \pm)$-ácido lisérgico $[( \pm)-1] 33 \%$

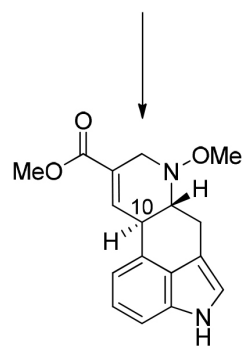

(士)-27 e 10-epi-27 (3:2) $67 \%$

Esquema 4. Síntese total do (士)-ácido lisérgico [( \pm )-1] publicada por Oppolzer e colaboradores em 1981 

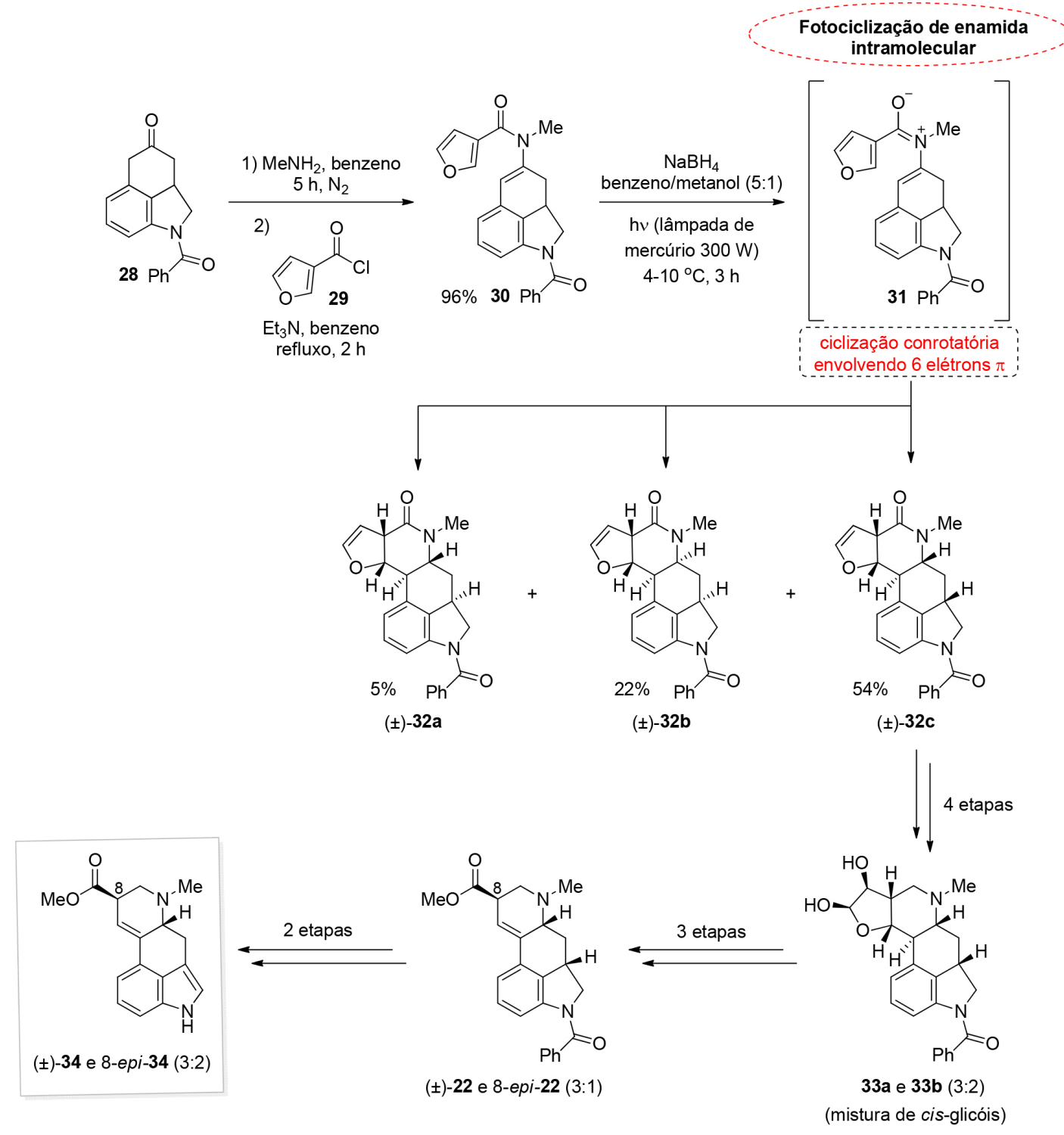

Esquema 5. Síntese formal do (土)-ácido lisérgico [( \pm )-1] desenvolvida por Ninomiya e colaboradores na década de 1980

quantitativo. A mistura contendo os álcoois $\mathbf{4 7}$ foi submetida a uma sequência de reações envolvendo eliminação, desproteção e ciclização intramolecular, promovendo a formação do composto ( \pm -48 e da mistura de epímeros constituída por ( \pm -49 e 8-epi-49 na proporção de 2:1. A mistura contendo os compostos ( \pm )-49 e 8-epi-49 foi convertida, após 3 etapas reacionais sem isolamento, na mistura conhecida dos epímeros ( \pm )-22 e 8-epi-22 em $60 \%$ de rendimento. ${ }^{13,16}$ $\mathrm{O}$ isômero $( \pm)-\mathbf{2 2}$ pode ser isolado após recristalização de EtOAc, estabelecendo a síntese formal do ( \pm )-ácido lisérgico $[( \pm)-\mathbf{1}] \cdot{ }^{19,20} \mathrm{~A}$ síntese desenvolvida por Kurihara e colaboradores foi concluída em 11 etapas, com rendimento global de $10,6 \%$, considerando a rota desenvolvida no artigo completo ${ }^{20}$ (Esquema 7).

Em 1988, Ortar e colaboradores publicaram a síntese formal do ( \pm )-ácido lisérgico [( \pm -1] empregando uma estratégia envolvendo reação de Heck e ciclização intramolecular ${ }^{21}$ (Esquema 8).

A cetona $\mathbf{5}$ foi convertida no vinil triflato $\mathbf{5 0}$, que foi submetido à reação de Heck envolvendo uma olefina funcionalizada, para a formação do intermediário (E)-53 em $26 \%$ de rendimento. O composto (E)-53 foi submetido à reação de desproteção em meio ácido, seguida por reação ácido-base, resultando através do intermediário 20, descrito na literatura, ${ }^{12,13}$ por uma ciclização intramolecular (espontânea), na formação dos epímeros (士)-22 e 8-epi-22 na proporção de 1,7:1 e em
$60 \%$ de rendimento. A síntese desenvolvida por Ortar e colaboradores foi concluída em 7 etapas, com rendimento global de 4,6\%, considerando o precursor do composto 51, metil 3-metilaminopropionato, como material de partida ${ }^{21}$ (Esquema 8).

Após alguns anos em esquecimento, o ( \pm )-ácido lisérgico [( \pm -1] retorna ao foco da química orgânica sintética nos anos 2000. Em 2004, Hendrickson e colaboradores publicaram uma rota curta, que utiliza como material de partida um derivado indólico e que não demanda etapas de proteção e desproteção do nitrogênio ${ }^{22}$ (Esquema 9).

A síntese do $( \pm)$-ácido lisérgico [( \pm$)-1]$ foi iniciada pela conversão de 4-bromoindol (54) no ácido borônico $\mathbf{5 5}$, que foi submetido ao acoplamento de Suzuki com o derivado do ácido isocinchomerônico 56 (sintetizado em duas etapas), resultando no intermediário $58 \mathrm{em}$ $91 \%$ de rendimento. A transformação do composto $\mathbf{5 8}$ no aldeído 59 e posterior ciclização intramolecular forneceu o álcool 60, que apresenta os quatro anéis da molécula alvo ( \pm )-1. Conforme informações do artigo, ${ }^{22}$ a desidratação/redução do álcool 60 levou à formação de um intermediário que pode ser isolado, mas sofreu decomposição em questão de horas. Portanto, a partir do composto 60 a síntese foi retomada sem isolamento dos intermediários e após duas etapas reacionais o $( \pm)$-ácido lisérgico $[( \pm)-1]$ foi obtido. A síntese total desenvolvida por Hendrickson e colaboradores foi concluída 

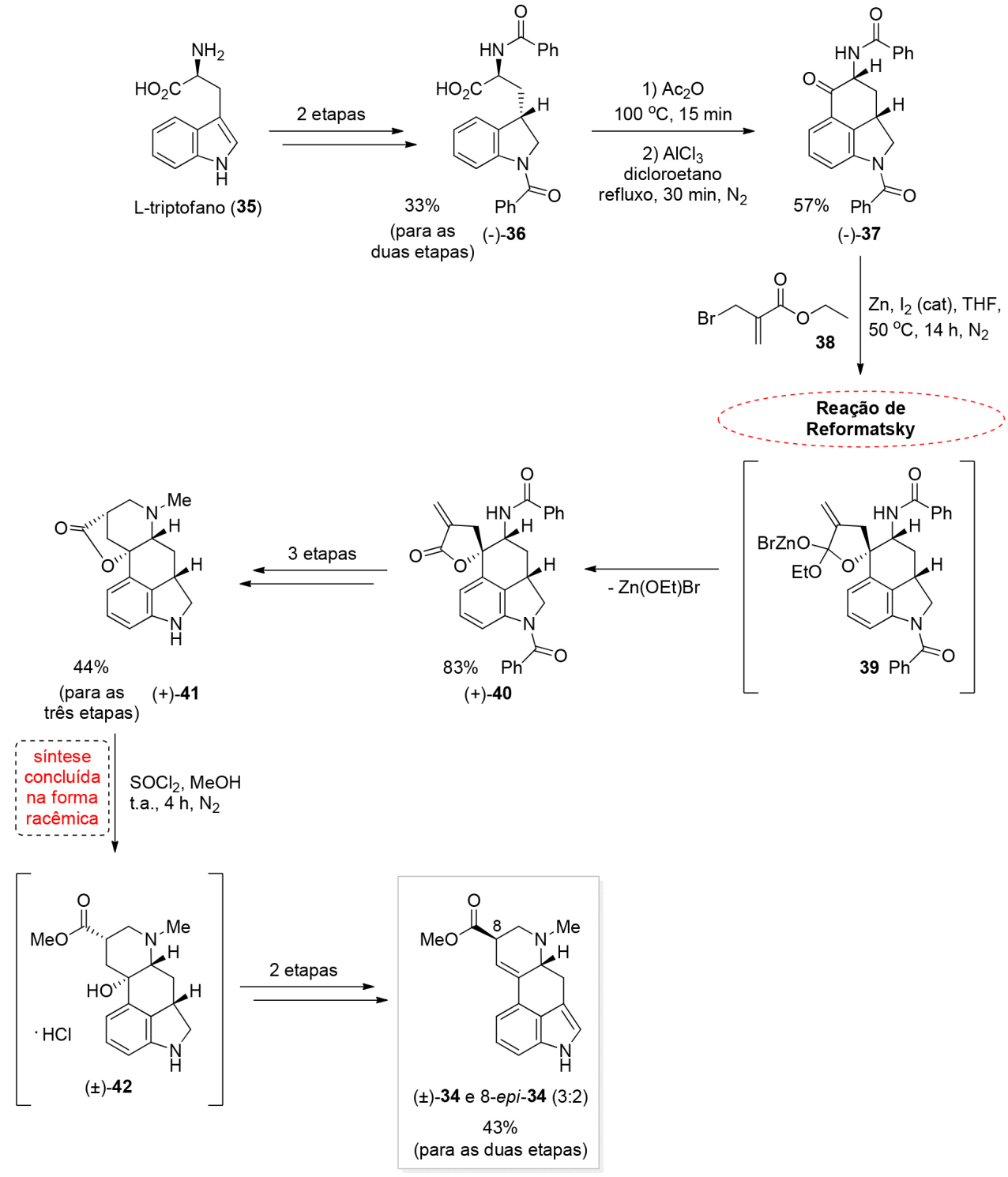

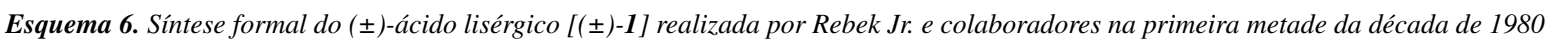

em 8 etapas, com rendimento global de $12 \%$, considerando o ácido isocinchomerônico como material de partida. Vale mencionar que o 4-bromoindol (54) é um reagente relativamente caro e foi preparado pelos autores $^{22}$ (Esquema 9).

A síntese total mais recente do ( \pm )-ácido lisérgico $[( \pm)-\mathbf{1}]$ foi publicada em 2008 por Fujii, Ohno e colaboradores envolvendo etapas chaves de catálise por compostos de coordenação contendo ouro $\left(\left[\left(\mathrm{Ph}_{3} \mathrm{PAu}\right)_{3} \mathrm{O}\right] \mathrm{BF}_{4}\right)$ e paládio $\left(\mathrm{Pd}\left(\mathrm{PPh}_{3}\right)_{4}\right)$. A rota desenvolvida, apesar de longa, mostrou-se interessante pela construção dos anéis $\mathrm{C}$ e $\mathrm{D}$ do esqueleto ergolínico em uma única etapa ${ }^{23}$ (Esquema 10).

O material de partida empregado foi 4-bromoindol (54), que após onze etapas reacionais resultou no éter propargil vinílico 61 . O composto 61 por rearranjo de Claisen catalisado por $\left[\left(\mathrm{Ph}_{3} \mathrm{PAu}\right)_{3} \mathrm{O}\right] \mathrm{BF}_{4}$ levou à formação do álcool alênico ( \pm -62. $\mathrm{O}$ composto $( \pm)$-62 por reação de Mitsunobu, seguida por desproteção resultou no aminoaleno $( \pm)-63$, que através de uma sequência de ciclizações catalisada por $\mathrm{Pd}\left(\mathrm{PPh}_{3}\right)_{4}$ promoveu a formação diastereosseletiva do intermediário ( \pm -65 em 65\% de rendimento, com relação trans:cis de 87:13. Com o esqueleto ergolínico formado, o ( \pm )-ácido lisérgico [( \pm -1] foi alcançado por meio de transformações de grupos funcionais. A síntese desenvolvida por Fujii, Ohno e colaboradores foi realizada em 22 etapas, com rendimento global de 3,2\% ${ }^{23}$ (Esquema 10).

\section{SÍNTESES QUIRAIS E ASSIMÉTRICAS}

Em 2004, Szántay e colaboradores publicaram a primeira síntese enantiomericamente pura (quiral) do (+)-ácido lisérgico [(+)-1] via resolução química de um intermediário ${ }^{24}$ (Esquema 11).

A síntese foi iniciada pela conversão do composto indólico 2 no intermediário 67, através de sequência de reações envolvendo acilação de Friedel-Crafts intramolecular, semelhante a que foi apresentada na rota desenvolvida por Woodward e colaboradores. ${ }^{9,10}$ Após cinco etapas reacionais, o intermediário $\mathbf{6 8}$ foi obtido e, depois de uma desproteção, convertido por uma condensação aldólica intramolecular no intermediário 8, que foi submetido a uma resolução com (-)-ácido dibenzoil L-tartárico fornecendo o composto (+)-8 em $38 \%$ de rendimento. A síntese seguiu somente com (+)-8 e os epímeros (+)-34 e 8-epi-34 foram obtidos e posteriormente convertidos em (+)-ácido lisérgico [(+)-1]. A síntese quiral desenvolvida pelo grupo de Szántay foi concluída em 15 etapas, com rendimento global de $0,7 \%{ }^{24}$ (Esquema 11).

Cinco anos mais tarde, em 2009, o grupo de Fukuyama publicou uma síntese formal assimétrica, relativamente longa, para o (+)-ácido lisérgico [(+)-1] empregando dessimetrização mediada pela lipase PS e ciclização catalisada por paládio ${ }^{25}$ (Esquema 12). 

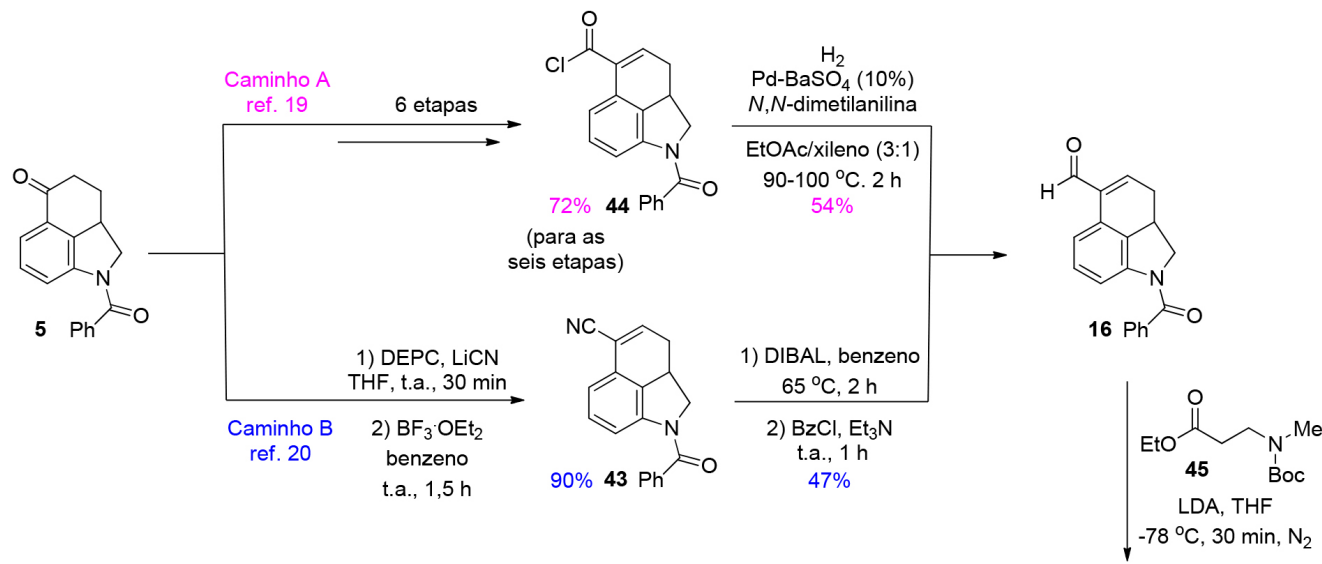

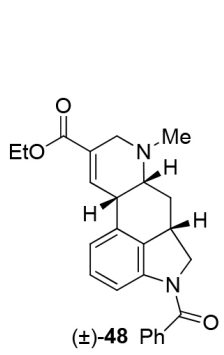

$7 \%$

$+$

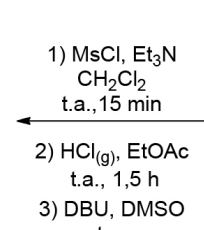

t.a.

t.a.

(para uma mistura de iastereoisômeros na proporção de 1:1,

com estereoquímicas relativas não determinadas)

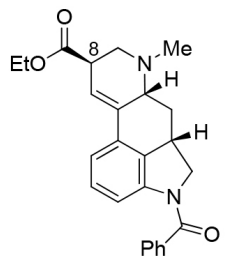

( \pm -49 e 8-epi-49 (2:1)

$42 \%$

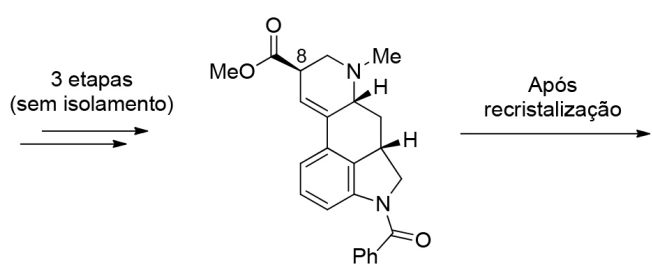

(士)-22 e 8-epi-22 (mistura)

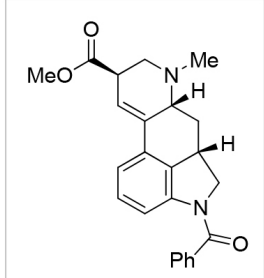

$( \pm)-22$

Esquema 7. Síntese formal do ( \pm )-ácido lisérgico [( \pm )-1] desenvolvida por Kurihara e colaboradores na segunda metade da década de 1980
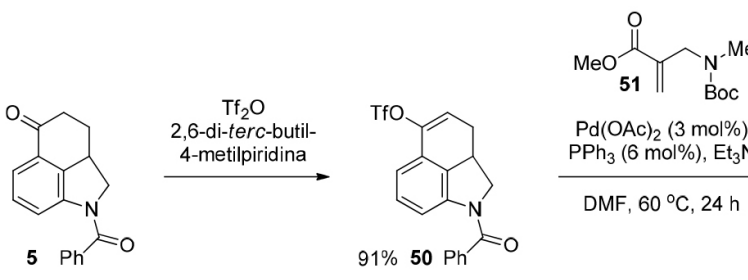

$\mathrm{Pd}(\mathrm{OAc})_{2}(3 \mathrm{~mol} \%)$ $\mathrm{PPh}_{3}(6 \mathrm{~mol} \%), \mathrm{Et}_{3} \mathrm{~N}$

DMF, $60^{\circ} \mathrm{C}, 24 \mathrm{~h}$

$91 \% 50 \mathrm{Ph}$
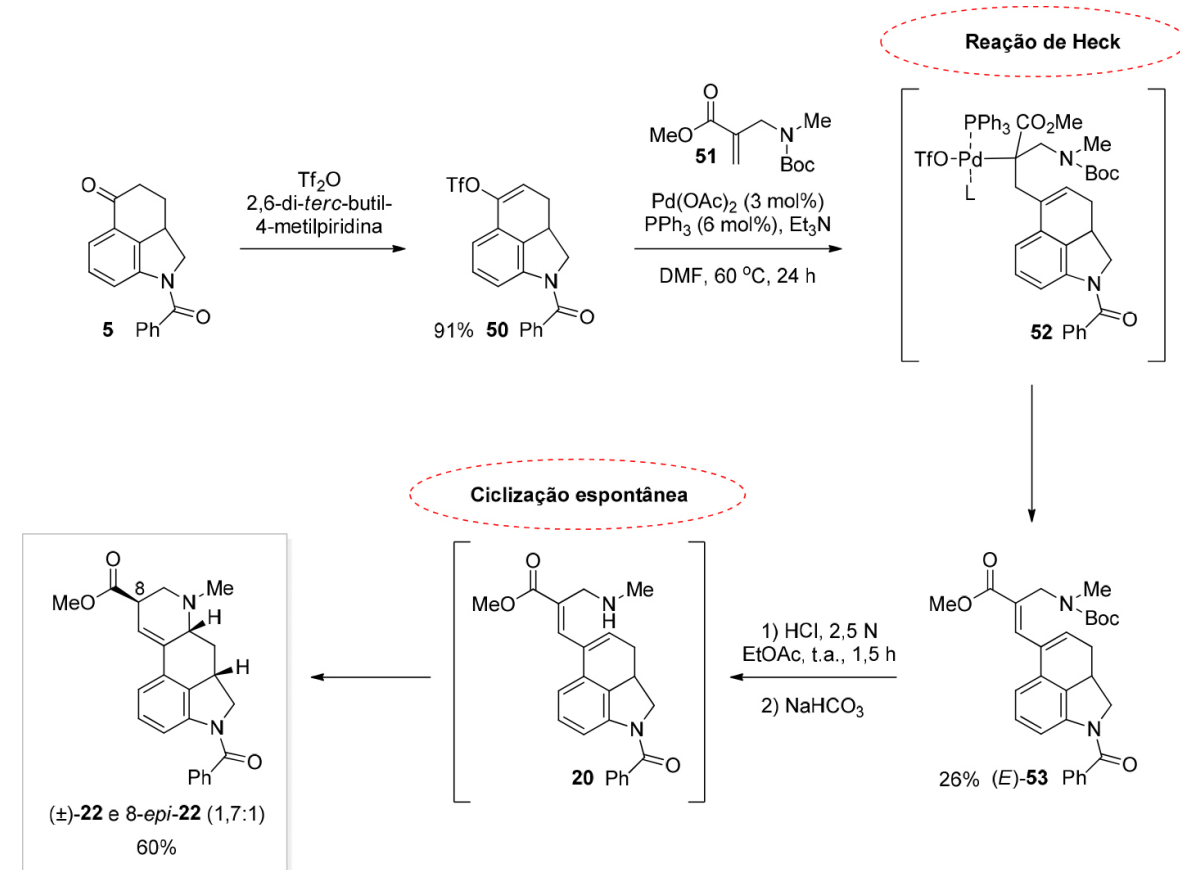

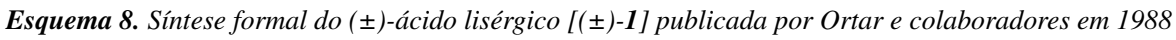



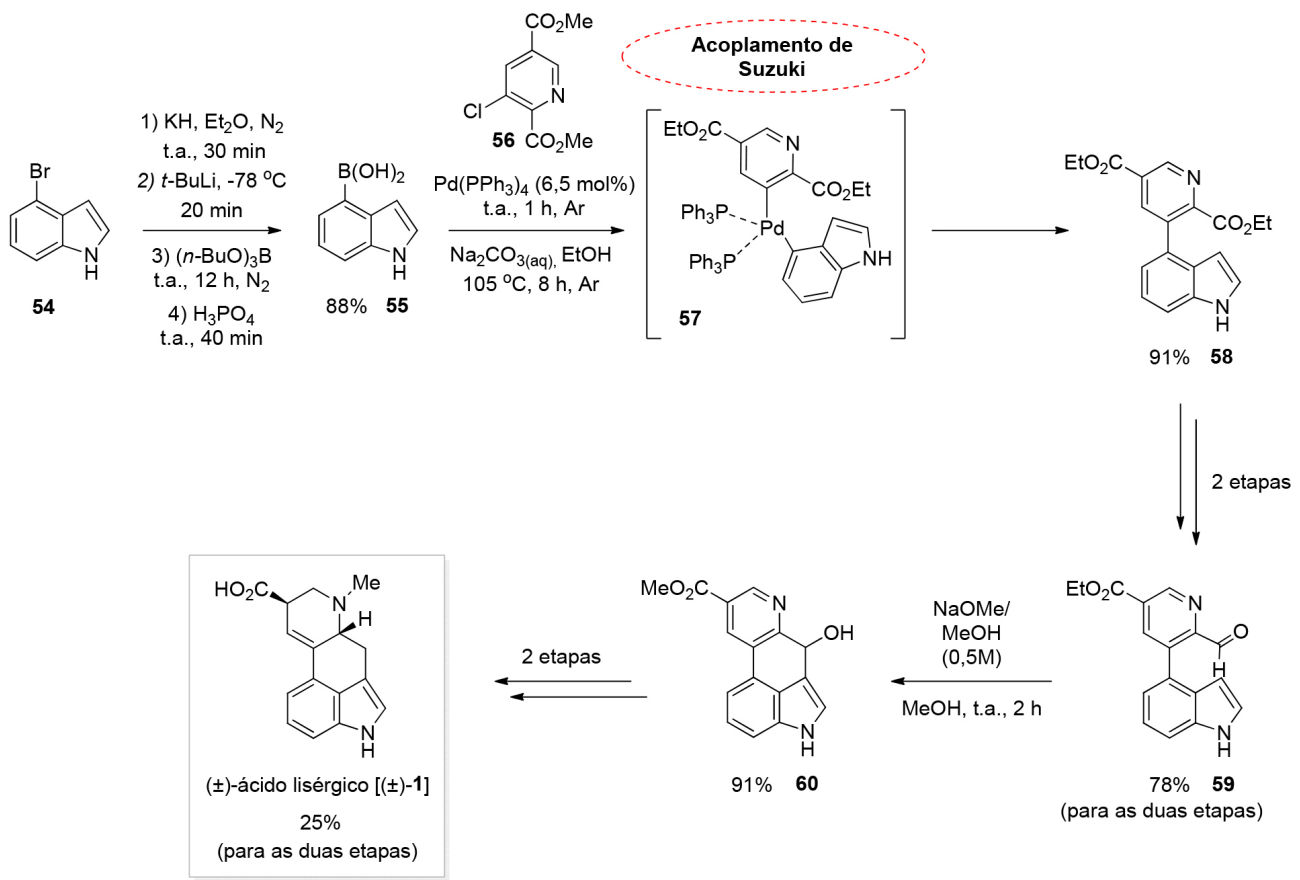

Esquema 9. Síntese total do (士)-ácido lisérgico [(士)-1] publicada por Hendrickson e colaboradores em 2004<smiles>Brc1cccc2[nH]ccc12</smiles>

54
11 etapas
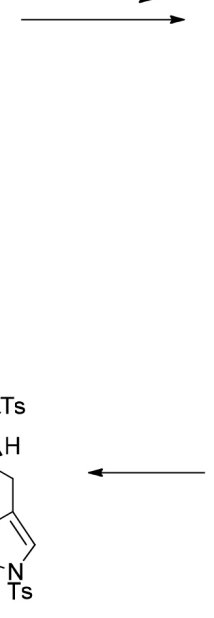

(士)-65 65\% $($ trans: cis $=87: 13)$

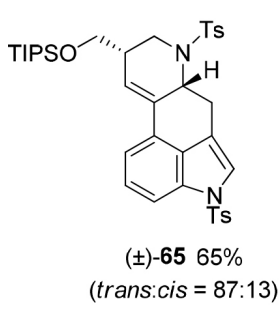

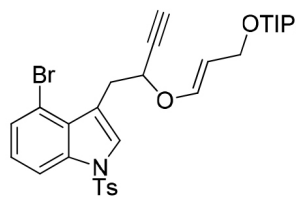

$6142 \%$

(para as onze etapas)

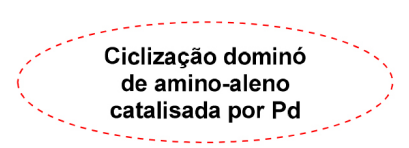

1) $\left[\left(\mathrm{Ph}_{3} \mathrm{PAu}\right)_{3} \mathrm{O}_{\mathrm{BF}}\right.$ (5 mol\%)

$\mathrm{CH}_{2} \mathrm{Cl}_{2}, 40^{\circ} \mathrm{C}, 10 \mathrm{~h}$

2) $\mathrm{NaBH}_{4}, \mathrm{MeOH}$

t.a., $1 \mathrm{~h}$

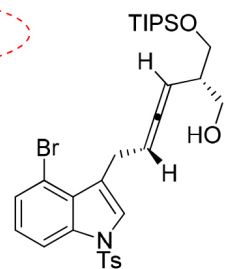

$( \pm)-6278 \%(r . d .=80: 20)$

1) TsNHFmoc $\mathrm{DEAD}, \mathrm{PPh}_{3}$

THF, t.a., 3 h

2) Piperidina DMF, t.a. , $50 \mathrm{~min}$
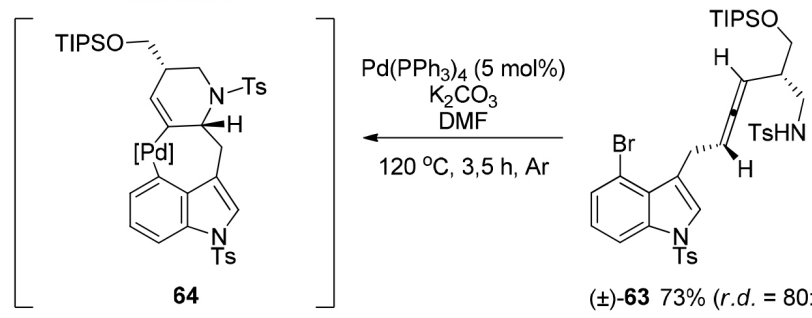

64

$( \pm)-6373 \%(r . d .=80: 20)$<smiles>COC(=O)[C@H]1C=C2c3cccc4[nH]cc(c34)C[C@H]2N(C)C1</smiles>

(士)-34 e 8-epi-34 (65:35) $38 \%$ (para as seis etapas)
1) $\mathrm{NaOH}(1 \mathrm{~N})$ $\underset{\mathrm{EtOH}, 35^{\circ} \mathrm{C}, 2 \mathrm{~h}}{\longrightarrow}$

2) $\mathrm{HCl}(0,1 \mathrm{~N})$ até $\mathrm{pH} 6,2$ $0^{\circ} \mathrm{C}, 2 \mathrm{~h}$

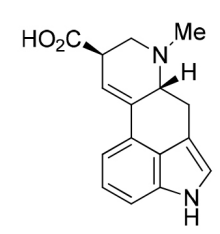

( \pm )-ácido lisérgico [( \pm -1] $54 \%$

Esquema 10. Síntese total do (土)-ácido lisérgico [( \pm )-1] publicada por Fujii, Ohno e colaboradores em 2008 


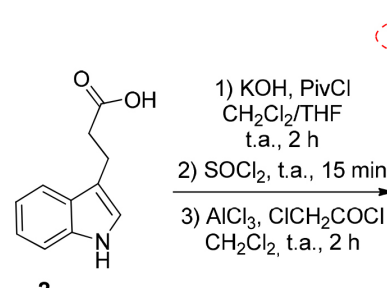

2
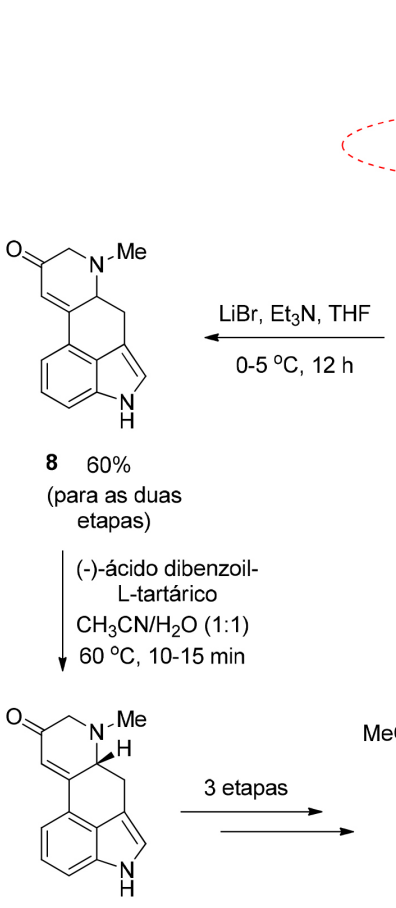

(+)-8 $38 \%$
Resolução

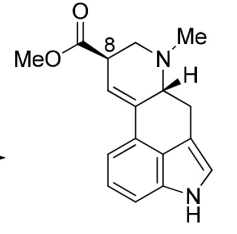

(+)-34 e 8-epi-34 (3:2) $39 \%$ (para as três etapas)

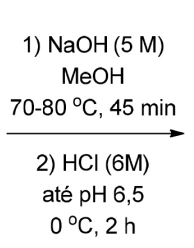

(+)-ácido lisérgico [(+)-1]
66

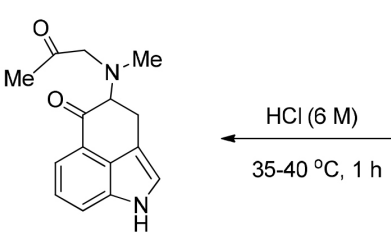

69

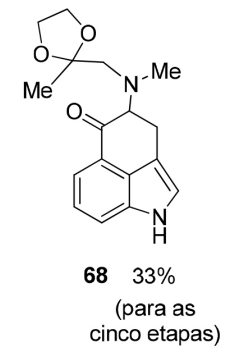

Esquema 11. Síntese total do (+)-ácido lisérgico [(+)-1] publicada por Szántay e colaboradores em 2004

A síntese foi iniciada com a dessimetrização do meso-1,3-diol 70 mediada pela lipase PS, seguida por transformação de grupo funcional, fornecendo o monoacetato opticamente ativo $\mathbf{7 1}$. O composto $\mathbf{7 1}$ foi transformado através de quinze etapas reacionais na nitro-olefina 72. Vale mencionar que valores das rotações ópticas específicas para os compostos $\mathbf{7 1}$ e $\mathbf{7 2}$ não foram informados. Após uma reação de adição conjugada no composto 72, uma mistura de epímeros $\mathbf{7 4}$ foi obtida em $\mathbf{7 5 \%}$ de rendimento. O grupo nitro presente na mistura de epímeros $\mathbf{7 4}$ foi reduzido seletivamente e protegido com Boc para a formação do intermediário $\mathbf{7 5}$. O composto $\mathbf{7 5}$ foi submetido a uma sequência de ciclizações resultando em $\mathbf{7 7}$, que possui o núcleo ergolínico e a estereoquímica do carbono 5 definida. O composto 77 foi transformado na mistura dos epímeros (+)-34 e 8-epi-34. A síntese formal assimétrica desenvolvida pelo grupo de Fukuyama foi concluída em 32 etapas, com rendimento global de $1,2 \%{ }^{25}$ (Esquema 12).

Ainda em 2009, Fukuyama e colaboradores publicaram outra síntese formal assimétrica mais curta para o (+)-ácido lisérgico [(+)-1], partindo da lactama 78, derivada do ácido L-glutâmico ${ }^{26}$ (Esquema 13).

A lactama $\mathbf{7 8}$ foi convertida através de quatro etapas reacionais no composto dibromado 79, que por reação eletrocíclica disrotatória envolvendo o intermediário 80 forneceu a di-hidropiridina $\mathbf{8 1}$. Depois de sete etapas reacionais o composto $\mathbf{8 1}$ foi convertido no cloreto de ácido 82, empregado em reação de substituição que forneceu o composto $\mathbf{8 4}$, que através de oito etapas reacionais foi convertido no intermediário $\mathbf{8 5}$. O composto $\mathbf{8 5}$ foi submetido a uma reação de Heck intramolecular, resultando no intermediário 87, que apresenta o esqueleto ergolínico completo. Com a desproteção do grupo Boc, o intermediário 88, sintetizado por Oppolzer e colaboradores, ${ }^{14}$ foi alcançado, configurando uma síntese formal assimétrica de 23 etapas, com um rendimento global de $0,2 \%{ }^{26}$ Vale mencionar que valores das rotações ópticas específicas para os compostos 79, 81, 82, 84, 85, 87 e 88 não foram informados. (Esquema 13).

Ao longo de 2011, o grupo de Fujii e Ohno, que havia publicado uma síntese racêmica em $2008,{ }^{23}$ divulgou suas contribuições que culminaram na síntese assimétrica do (+)-ácido lisérgico $[(+)-\mathbf{1}]^{27,28}$ (Esquema 14).

O grupo de Fujii e Ohno reportou duas rotas para a obtenção de (+)-1 empregando 4-bromoindol (54) como material de partida, utilizando a mesma química da publicação de $2008^{23}$ (Esquema 10), no entanto, envolvendo ciclizações dominó catalisadas por paládio de amino-alenos enantiomericamente enriquecidos..$^{27,28}$ Na primeira rota (Esquema 14 - caminho A), a tosilamida alênica (-)-91 foi obtida através do intermediário (-)-89, formado a partir de um acoplamento cruzado entre um aldeído derivado de 54 e um alquino quiral (preparado em sete etapas a partir do $(S$ )-aldeído de Garner), seguido de uma oxidação de Dess-Martin e de uma redução com $(R)$-alpino-borana, para definição do centro estereogênico no carbono da hidroxila, necessária para a formação do aleno quiral. ${ }^{27}$ Na segunda rota (Esquema 14 - caminho B), a quiralidade de (-)-91 


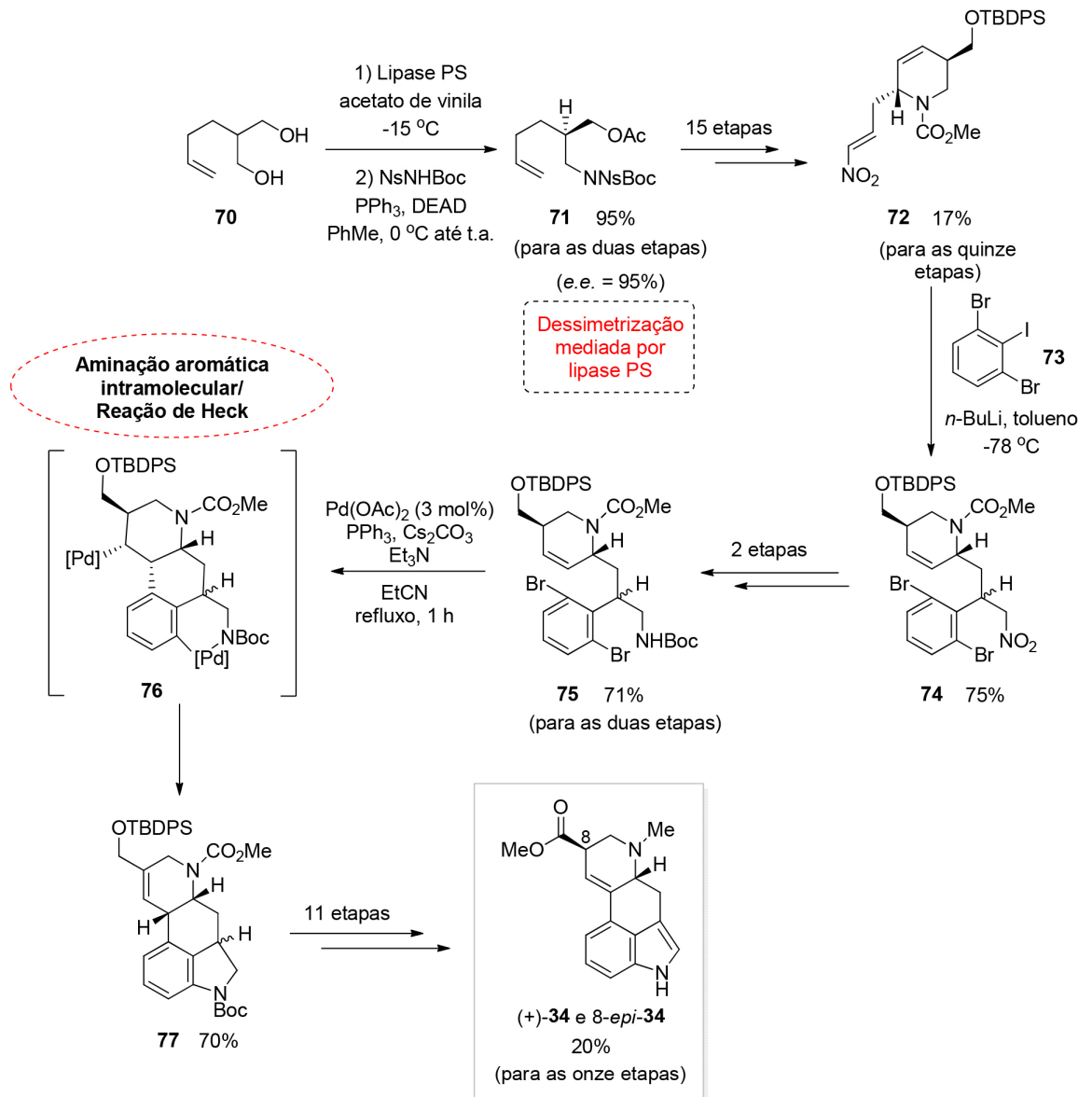

Esquema 12. Síntese formal do (+)-ácido lisérgico [(+)-1] publicada por Fukuyama e colaboradores em 2009

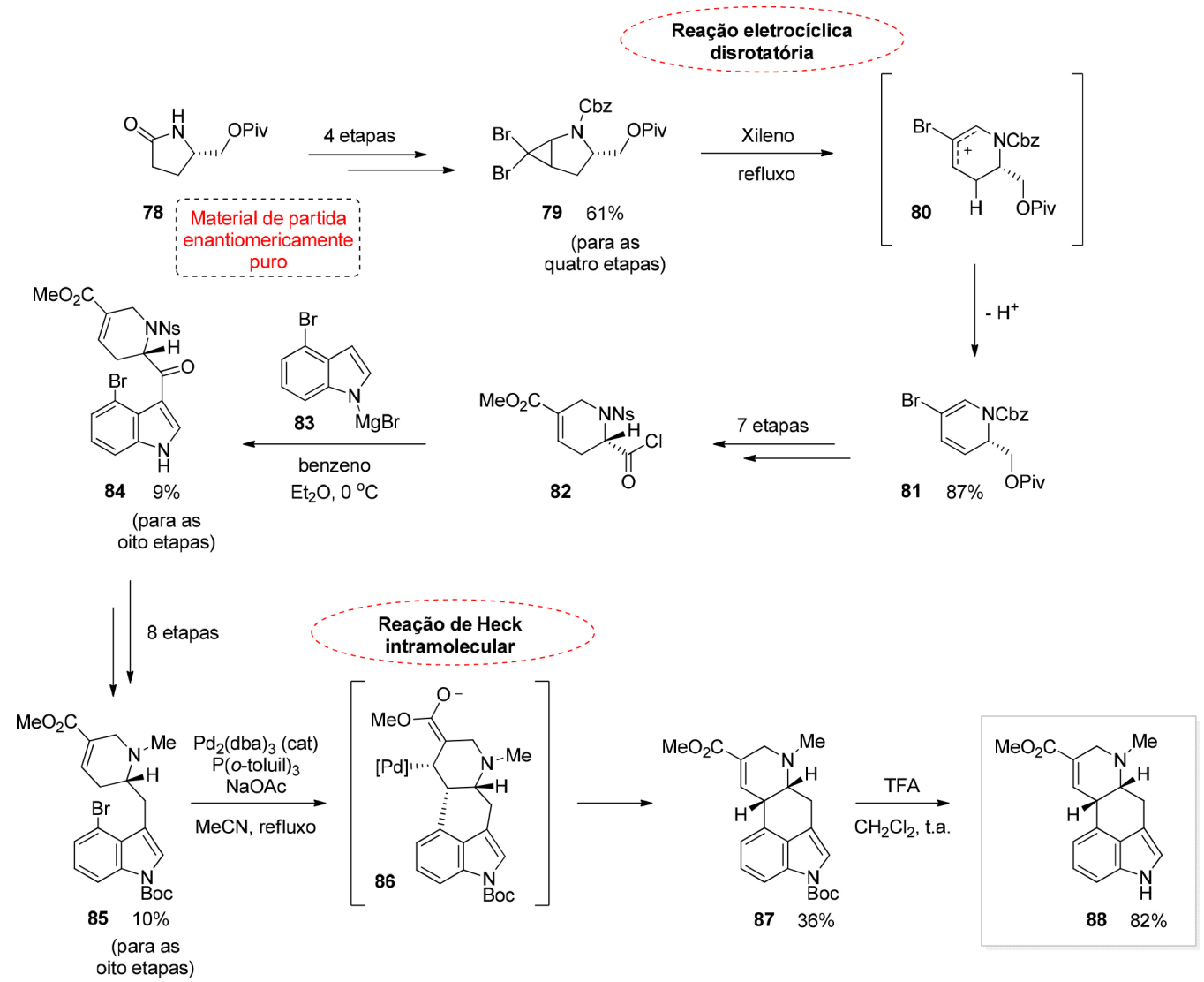

Esquema 13. Síntese formal do (+)-ácido lisérgico [(+)-1] publicada pelo grupo de Fukuyama em 2009 


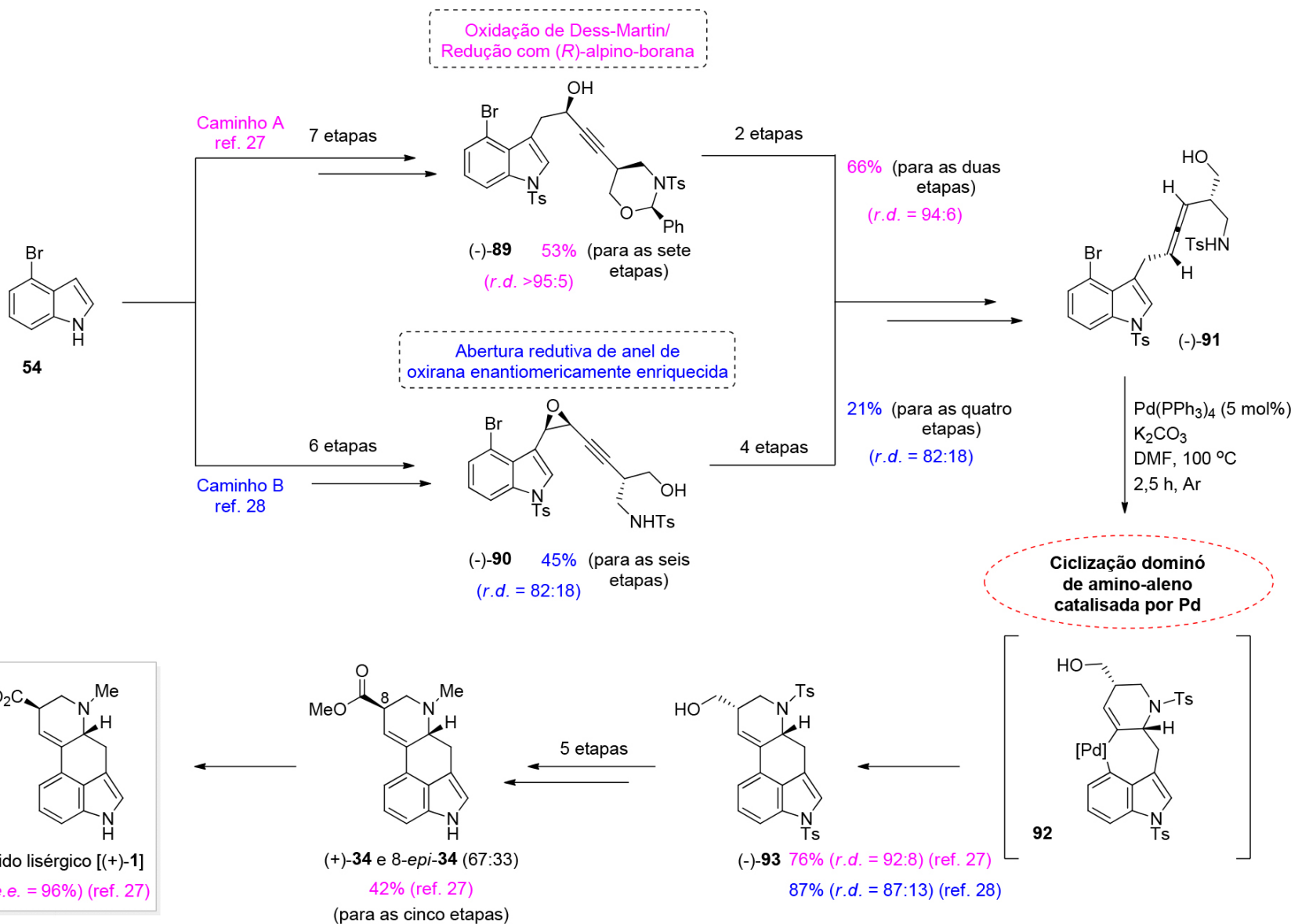

Esquema 14. Sínteses total e formal do (+)-ácido lisérgico [(+)-1] publicadas por Fujii, Ohno e colaboradores em 2011

foi produzida através de uma reação de abertura redutiva de anel da oxirana quiral (-)-90, obtida a partir de um acomplamento de Sonogashira entre um brometo vinílico derivado de 54 e um alquino quiral (preparado em cinco etapas a partir do $(S)$-aldeído de Garner), seguida de uma epoxidação assimétrica, dispensando as etapas de oxidação e redução presentes na primeira rota. ${ }^{28} \mathrm{O}$ aminoaleno (-)-91 foi submetido a uma sequência de ciclizações catalisada por $\mathrm{Pd}\left(\mathrm{PPh}_{3}\right)_{4}$ promovendo a formação o álcool (-)-93. A síntese formal termina com a obtenção do intermediário (-)-93 em 12 etapas, com rendimento global de 5,0\% ${ }^{28}$ (Esquema 14 - caminho B), enquanto que a síntese total do (+)-ácido lisérgico [(+)-1] foi concluída em 19 etapas, com rendimento global de 2,5\% ${ }^{27}$ (Esquema 14 - caminho A). Ambos os rendimentos globais foram calculados considerando o $(S)$-aldeído de Garner como material de partida.

Em 2011, Jia e colaboradores publicaram uma rota sintética que empregava transformações catalisadas por metais nas etapas de construção dos anéis B, C e D do esqueleto ergolínico do (+)-ácido lisérgico $[(+)-1]^{29}$ (Esquema 15).

A síntese teve início pela transformação de ácido D-glutâmico (94) no intermediário (+)-95, passando por uma etapa de formação do anel indólico catalisada por Pd (formação do anel B). Após oito etapas o dieno (+)-96 foi obtido e convertido no intermediário (-)98, através de reação de metátese de fechamento de anel utilizando o catalisador de Grubbs de segunda geração (formação do anel D). O composto (-)-98 foi submetido a uma etapa de isomerização da dupla formando o intermediário 99, que através de uma reação de Heck intramolecular resultou no derivado ergolínico (-)-87 em 84\% de rendimento (formação do anel C). O (+)-ácido lisérgico [(+)-1] foi obtido por tratamentos com $\mathrm{KOH}$ e então com $\mathrm{HCl}$. A síntese assimétrica desenvolvida por Jia e colaboradores foi concluída em
12 etapas, com rendimento global de $12,7 \%$, considerando (+)-95 como material de partida, ou em 20 etapas, com rendimento global de 5,0\%, considerando ácido D-glutâmico (94) como material de partida $^{29}$ (Esquema 15).

Dois anos mais tarde, em 2013, o grupo de Jia publicou uma nova estratégia, ainda utilizando catálises metálicas para as construções dos anéis B, C e D, no entanto, mudando a ordem de formação dos anéis, encurtando a síntese do (+)-ácido lisérgico [(+)-1] em oito etapas $^{30}$ (Esquema 16).

A síntese foi iniciada pela reação tricomponente envolvendo o aldeído 103, brometo de alila (101) e $(R)-(+)-2-$ metil-2propansulfinamida (102), na presença de índio metálico e tetraetóxido de titânio, que forneceu de maneira diastereosseletiva a alilamina 104. A reação de $N$-alquilação do composto 104 resultou no dieno (+)-106 como produto majoritário em $74 \%$ de rendimento. Posteriormente, o núcleo ergolínico começou a ser construído pela formação do anel $\mathrm{D}$, por reação de metátese de fechamento de anel, resultando no composto (-)-108, que foi transformado no intermediário (-)-109. A construção do anel B foi realizada pela reação entre o composto (-)-109 e 3-cloro-2-iodoanilina (110) catalisada por paládio resultando no intermediário 112 (que não teve o valor de rotação óptica específica informado). Transformações de grupos funcionais, incluindo isomerização de ligação dupla, forneceram o intermediário $\mathbf{1 1 3}$, que foi submetido à reação de Heck intramolecular, considerada um desafio para derivados de 4-clorotriptofanos, promovendo a formação do intermediário (-)-87, contendo o anel $\mathrm{C} \mathrm{e}$, consequentemente, o esqueleto ergolínico, em $25 \%$ de rendimento. $\mathrm{O}$ composto (-)-87 foi convertido no (+)-ácido lisérgico [(+)-1] através de transformações conhecidas. A nova síntese assimétrica desenvolvida pelo grupo de Jia foi concluída em 


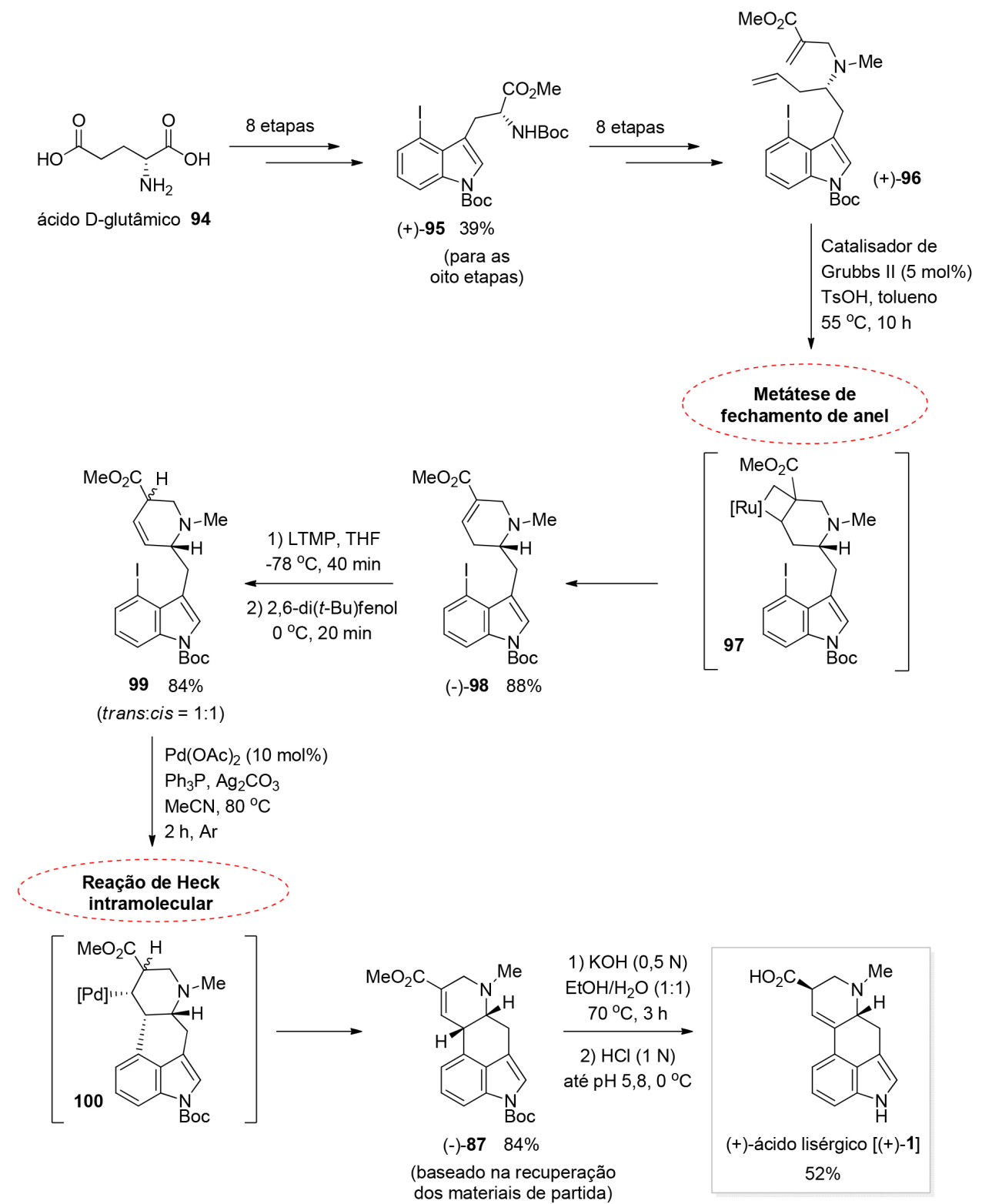

Esquema 15. Síntese total do (+)-ácido lisérgico [(+)-1] publicada por Jia e colaboradores em 2011

12 etapas, com rendimento global de $1,1 \%$, partindo do composto $\mathbf{1 0 3}^{30}$ (Esquema 16).

Em 2013, o grupo de Fukuyama volta a aparecer com uma abordagem para a síntese assimétrica do (+)-ácido lisérgico [(+)-1], inspirada nas sínteses reportadas pelo grupo de $\mathrm{Jia},{ }^{29,30}$ empregando metátese de fechamento de anel para obter o anel D e reação de Heck intramolecular para formar o anel $\mathrm{C}$, no entanto, através de materiais de partida completamente distintos, incluindo o composto indólico 116, que apresenta o anel $\mathrm{B}^{31}$ (Esquema 17).

Uma novidade presente na síntese foi o emprego de reações estereosseletivas para a obtenção dos intermediários (+)-115 e (+)117, que foram conectados através de uma aminação redutiva, seguida de proteção com Boc, formando o dieno (+)-118. O composto (+)118 foi submetido à metátese de fechamento de anel resultando no intermediário (-)-120, que apresenta os anéis A, B e D. A formação do anel $\mathrm{C}$ ocorreu quando o composto (-)-120 foi submetido à reação de Heck intramolecular resultando no intermediário (-)-122, que possui o esqueleto ergolínico e pode ser convertido através de onze etapas reacionais no (+)-ácido lisérgico [(+)-1]. A síntese desenvolvida por Fukuyama e colaboradores, apesar de possuir
19 etapas reacionais, apresentou um rendimento global bastante satisfatório de $12,1 \%$ (considerando o composto 114 como material de partida), ${ }^{31}$ quando comparada às sínteses quirais/assimétricas publicadas anteriormente ${ }^{24-30}$ (Esquema 17).

A síntese assimétrica mais recente do (+)-ácido lisérgico [(+)-1] também foi fruto dos esforços do grupo de pesquisa liderado por Fukuyama, que apresentou ao longo da síntese um método inovador para a formação de ligação C-C, envolvendo a abertura de um anel aziridínico $^{32}$ (Esquema 18).

A síntese foi iniciada pela introdução de auxiliar quiral no ácido (2-bromofenil)acético (123), seguida por reação de alilação diastereosseletiva resultando no intermediário (-)-125, que por reação de redução com $\mathrm{LiAlH}_{4}$ promoveu a formação do álcool (+)126. Após cinco etapas, entre elas uma reação de Mitsunobu e uma aminação arílica mediada por cobre, a indolina (-)-127 foi obtida. A introdução de auxiliar quiral no intermediário (-)-127 forneceu o composto (-)-128, que por sequência de reações, envolvendo adição à carbonila diastereosseletiva e rearranjo de Curtius, produziu o intermediário (-)-129. O composto (-)-129 resultou na formação da aziridina (-)-130. Em seguida, o composto (-)-130 na presença 

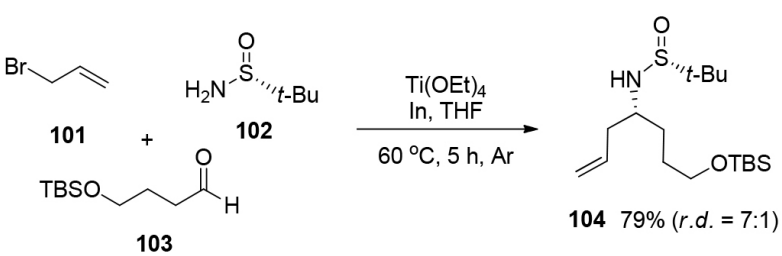

$10479 \%(r . d .=7: 1)$
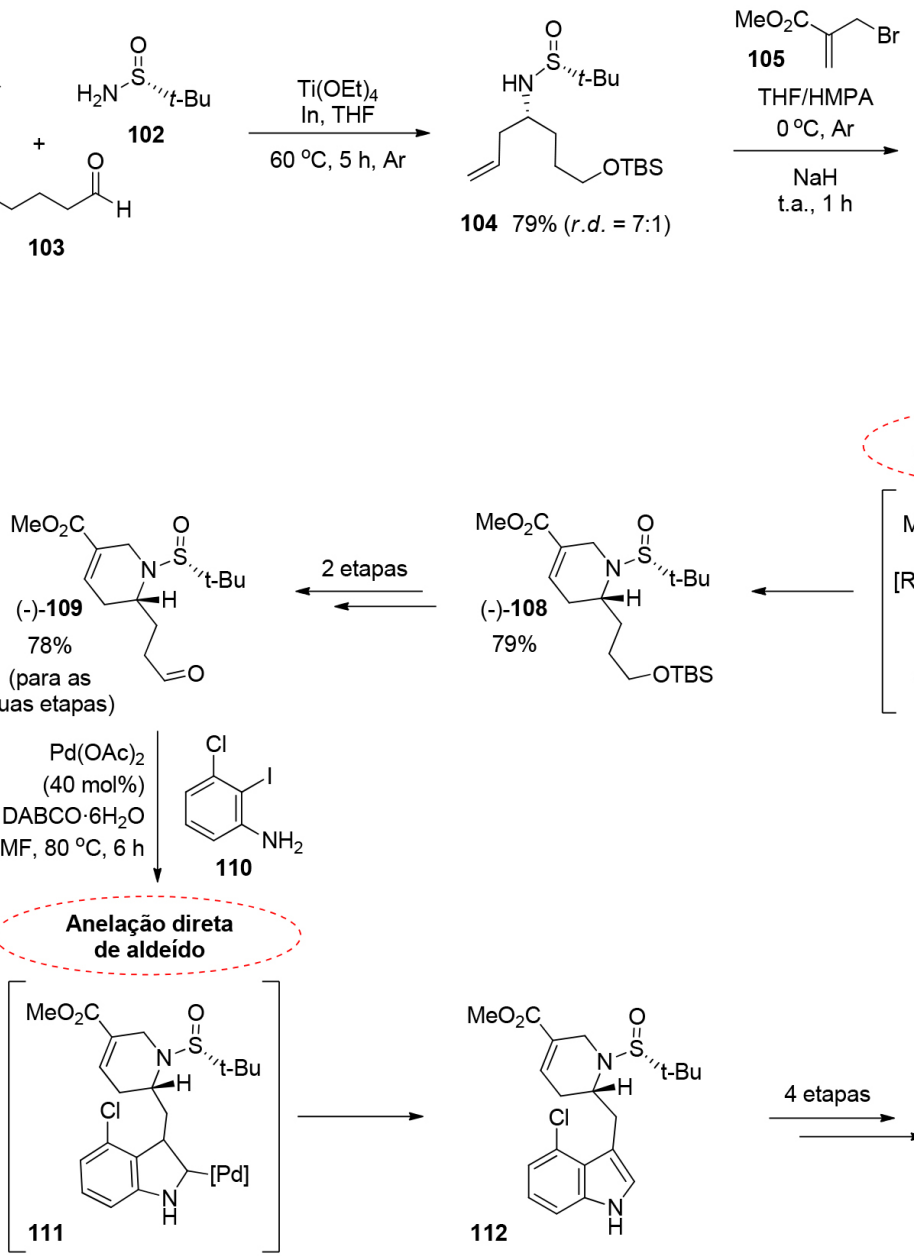

$\mathrm{MeO}_{2} \mathrm{C}$

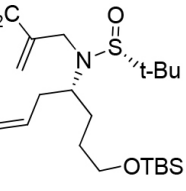

(+)-106 74\%

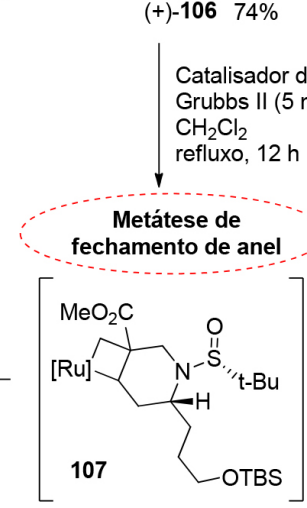

112
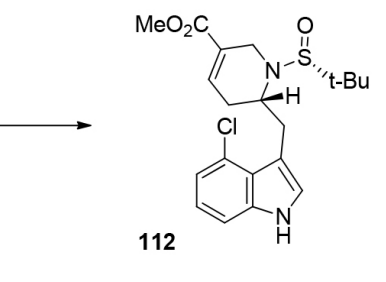

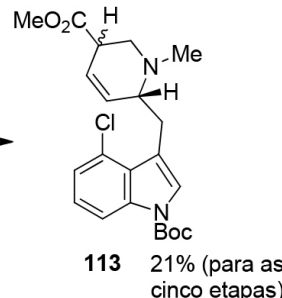

(2:1)

$\mathrm{Pd}_{2}(\mathrm{dba})_{3} \cdot \mathrm{CHCl}_{3}$ (50 mol\%) $\mathrm{P}(t-\mathrm{Bu})_{3} \cdot \mathrm{HBF}_{4}$ $\mathrm{Cy}_{2} \mathrm{MeN}$, dioxano $100^{\circ} \mathrm{C}, 1,5 \mathrm{~h}, \mathrm{Ar}$

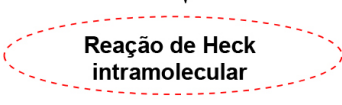

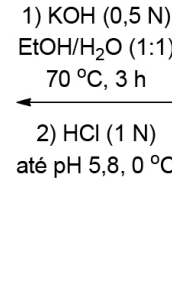

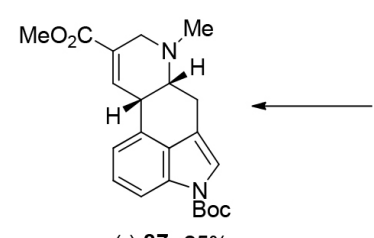

(-)-87 25\%

(baseado na recuperação do material de partida)

Esquema 16. Síntese total do (+)-ácido lisérgico [(+)-1] publicada por Jia e colaboradores em 2013

de ácido de Lewis promoveu a formação do intermediário (-)-131 em $69 \%$ de rendimento. O composto (-)-131 foi transformado no intermediário (-)-132, que por reação de Mitsunobu intramolecular resultou no composto (-)-134, contendo o núcleo ergolínico. Através de cinco etapas reacionais, envolvendo desproteção e oxidação, o composto (-)-134 resultou na formação do intermediário (-)-135, que foi convertido no (+)-ácido lisérgico [(+)-1]. A síntese total assimétrica foi concluída em 30 etapas, com $0,1 \%$ de rendimento global $^{32}$ (Esquema 18).

\section{CONCLUSÕES}

Os alcaloides ergolínicos apresentam estruturas relativamente complexas e propriedades farmacológicas variadas. O (+)-ácido lisérgico [(+)-1] pode ser considerado o principal representante dos alcaloides ergolínicos, destacando-se como precursor de diversas substâncias com propriedades farmacológicas pronunciadas. Nesse contexto, a sua importância como alvo sintético torna-se indiscutível e, atualmente, diversas estratégias para a sua síntese estão descritas na literatura. Neste artigo de revisão abordamos em ordem cronológica 
<smiles>C/C=C/C(=O)N1C(=O)OC(C)(C)[C@H]1Br</smiles>

114<smiles></smiles>

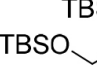

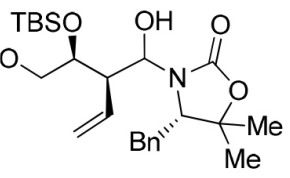

(+)-115 49\% (para as três etapas)<smiles>O=Cc1cn([As])c2cccc(Br)c12</smiles>

116<smiles></smiles>

(+)-117 70\%

(para as quatro etapas)

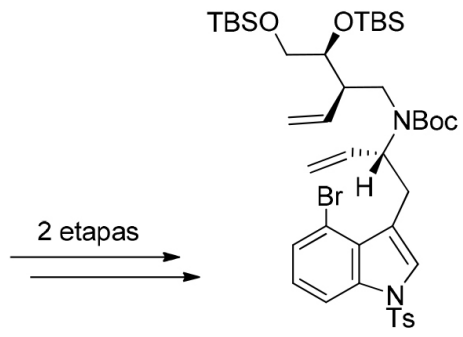

(+)-118 60\%

(para as duas etapas)

Catalisador de Grubbs II (3 mol\%) tolueno, $80^{\circ} \mathrm{C}, 1 \mathrm{~h}$

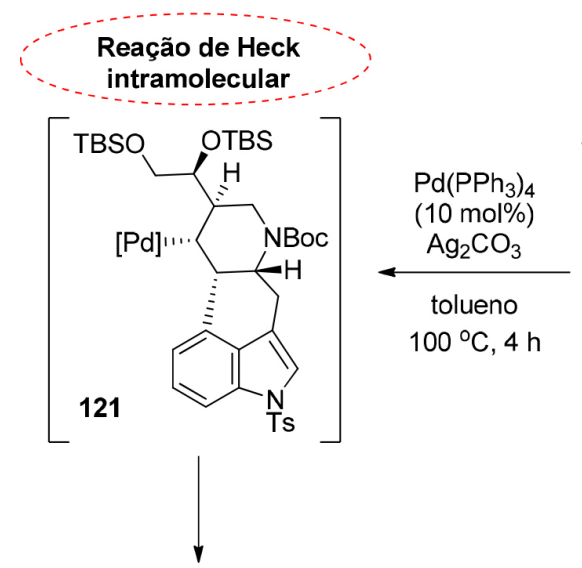

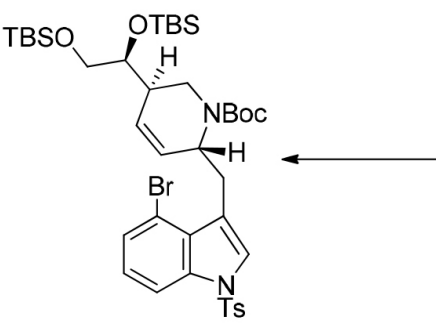

(-)-120 99\%

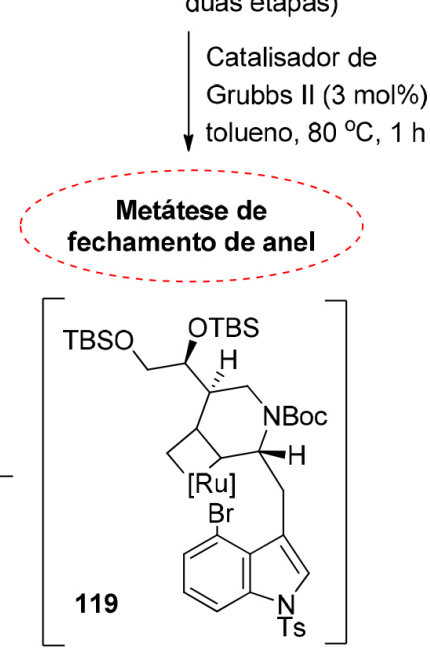

119<smiles>CN1CC(C(=O)O)C=C2c3cccc4[nH]cc(c34)C[C@H]21</smiles>

(+)-ácido lisérgico $[(+)-1]$

$33 \%$

(para as onze etapas)

Esquema 17. Síntese total do (+)-ácido lisérgico [(+)-1] publicada por Fukuyama e colaboradores em 2013

as sínteses totais e formais do ácido lisérgico (1), separando-as em sínteses racêmicas e quirais/assimétricas. Até o momento, existem 24 sínteses descritas na literatura, a saber: 11 sínteses totais e 13 formais; 15 sínteses racêmicas e 9 quirais/assimétricas. Dentre as sínteses racêmicas, as rotas que apresentaram menor número de etapas foram as dos grupos de Julia e de Ortar (7 etapas), no entanto, a mais eficiente em termos de rendimento global foi a de Ramage e colaboradores (14\%). Considerando as sínteses quirais/assimétricas, as rotas mais curtas foram as dos grupos de Jia e de Fujii e Ohno (12 etapas), contudo, a mais eficiente foi a de Fukuyama e colaboradores $(12,1 \%)$. Realizando uma avaliação rigorosa, não podemos deixar de mencionar que as sínteses mais eficientes para o (+)-ácido lisérgico $[(+)-1]$ ainda são relativamente longas e, consequentemente, poderiam ser aprimoradas.

\section{AGRADECIMENTOS}

Agradecemos à Fundação de Amparo à Pesquisa do Estado de São Paulo (FAPESP) (Processo No 2020/12530-8) e ao Conselho Nacional de Desenvolvimento Científico e Tecnológico (CNPq) pelo apoio financeiro. T. R. C. S. agradece à Coordenação de Aperfeiçoamento de Pessoal de Nível Superior (CAPES) pela bolsa de doutorado. 


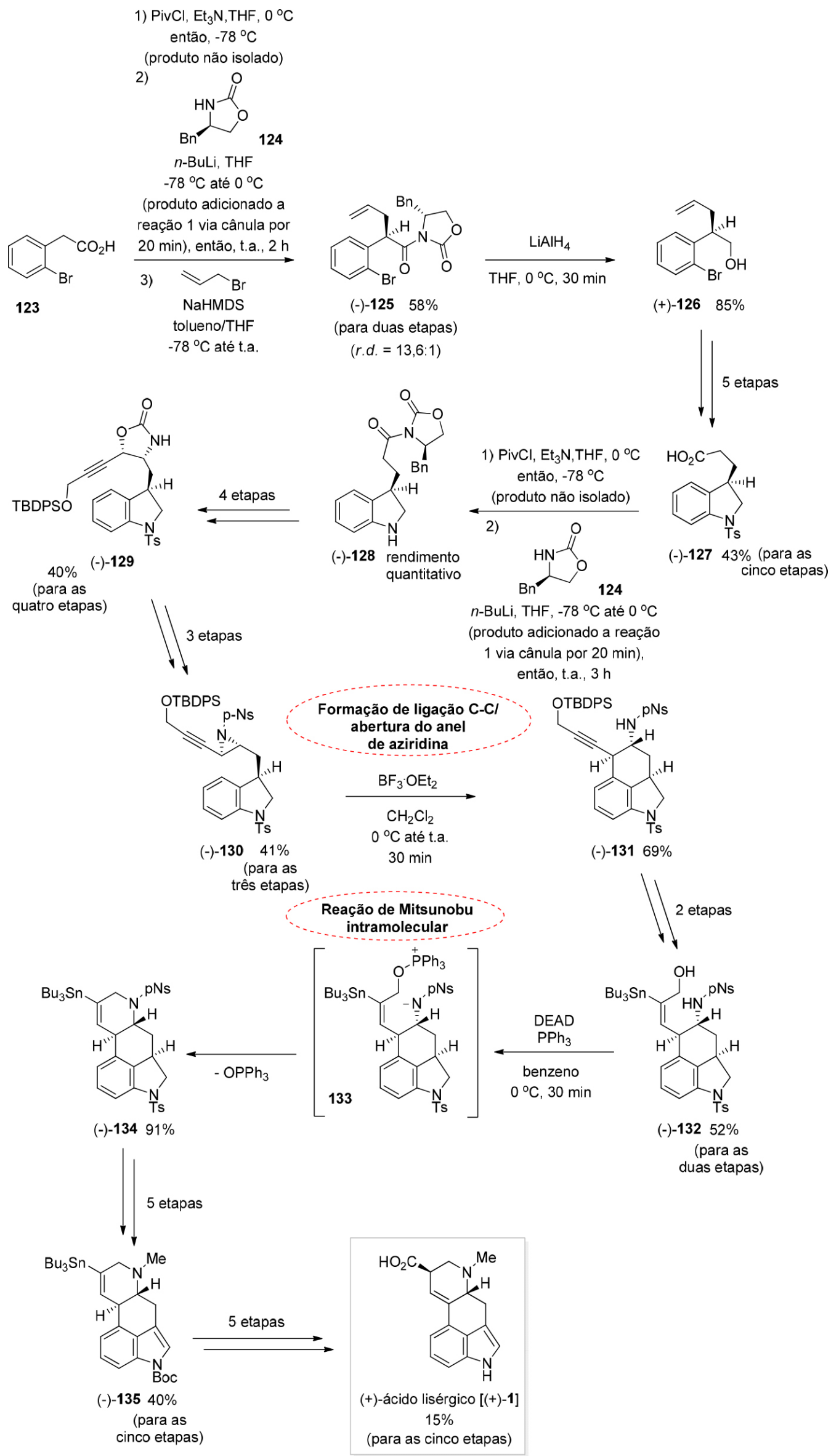

Esquema 18. Síntese total do (+)-ácido lisérgico [(+)-1] publicada por Fukuyama e colaboradores em 2018 


\section{REFERÊNCIAS}

1. Liu, H.; Jia, Y.; Nat. Prod. Rep. 2017, 34, 411; Jacobs, W.; Craig, L.; J. Biol. Chem. 1934, 104, 547.

2. Chen, J.-J.; Han, M.-Y.; Gong, T.; Yang, J.-L.; Zhu, P.; RSC Adv. 2017 , 7, 27384.

3. Wallwey, C.; Li, S.-M.; Nat. Prod. Rep. 2011, 28, 496.; Floss, H. G.; Tetrahedron 1976, 32, 873.

4. Scientific Opinion on Ergot alkaloids in food and feed, EFSA Panel on Contaminants in the Food Chain (CONTAM), EFSA Journal 2012, 10, 2798, DOI:10.2903/j.efsa.2012.2798.

5. https://go.drugbank.com/, acessada em Março 2021.

6. McCabe, S. R.; Wipf, P.; Org. Biomol. Chem. 2016, 14, 5894.

7. Moldvai, I.; Temesvári-Major, E.; Incze, M.; Dörnyei, G.; Szentirmay, É.; Szántay, C.; Helv. Chim. Acta 2005, 88, 1344.

8. Somei, M.; Yokoyama, Y.; Murakami, Y.; Ninomiya, I.; Kiguchi, T.; Naito, T. Em The Alkaloids; Cordell, G. A., ed.; Academic Press: San Diego, CA, 2000; Vol. 54, pp 191.

9. Kornfeld, E. C.; Fornefeld, E. J.; Kline, G. B.; Mann, M. J.; Jones, R. G.; Woodward, R. B.; J. Am. Chem. Soc. 1954, 76, 5256.

10. Kornfeld, E. C.; Fornefeld, E. J.; Kline, G. B.; Mann, M. J.; Morrison, D. E.; Jones, R. G.; Woodward, R. B.; J. Am. Chem. Soc. 1956, 78, 3087

11. Julia, M.; LeGoffic, F.; Igolen, J.; Baillarge, M.; Tetrahedron Lett. 1969, $10,1569$.

12. Armstrong, V. W.; Coulton, S.; Ramage, R.; Tetrahedron Lett. 1976, 17, 4311.

13. Ramage, R.; Armstrong, V. W.; Coulton, S.; Tetrahedron 1981, 37, 157.

14. Oppolzer, W.; Francotte, E.; Bättig, K.; Helv. Chim. Acta 1981, 64, 478.
15. Kiguchi, T.; Hashimoto, C.; Naito, T.; Ninomiya, I.; Heterocycles 1982 , 19, 2279.

16. Ninomiya, I.; Hashimoto, C.; Kiguchi, T.; Naito, T.; J. Chem. Soc., Perkin Trans. 1 1985, 941.

17. Rebek Jr., J.; Tai, D. F.; Tetrahedron Lett. 1983, 24, 859.

18. Rebek Jr., J.; Tai, D. F.; Shue, Y. K.; J. Am. Chem. Soc. 1984, 106, 1813.

19. Kurihara, T.; Terada, T.; Yoneda, R.; Chem. Pharm. Bull. 1986, 34, 442.

20. Kurihara, T.; Terada, T.; Harusawa, S.; Yoneda, R.; Chem. Pharm. Bull. 1987, 35, 4793.

21. Cacchi, S.; Ciattini, P. G.; Morera, E.; Ortar, G.; Tetrahedron Lett. 1988, 29, 3117.

22. Hendrickson, J. B.; Wang, J.; Org. Lett. 2004, 6, 3.

23. Inuki, S.; Oishi, S.; Fujii, N.; Ohno, H.; Org. Lett. 2008, 10, 5239.

24. Moldvai, I.; Temesvári-Major, E.; Incze, M.; Szentirmay, É.; Gács-Baitz, E.; Szántay, C.; J. Org. Chem. 2004, 69, 5993.

25. Kurokawa, T.; Isomura, M.; Tokuyama, H.; Fukuyama, T.; Synlett 2009, 775 .

26. Fukuyama, T.; Inoue, T.; Yokoshima, S.; Heterocycles 2009, 79, 373

27. Inuki, S.; Iwata, A.; Oishi, S.; Fujii, N.; Ohno, H.; J. Org. Chem. 2011, 76, 2072.

28. Iwata, A.; Inuki, S.; Oishi, S.; Fujii, N.; Ohno, H.; J. Org. Chem. 2011, 76, 5506.

29. Liu, Q.; Jia, Y.; Org. Lett. 2011, 13, 4810.

30. Liu, Q.; Zhang, Y.; Xu, P.; Jia, Y.; J. Org. Chem. 2013, 78, 10885.

31. Umezaki, S.; Yokoshima, S.; Fukuyama, T.; Org. Lett. 2013, 15, 4230.

32. Kanno, R., Yokoshima, S., Kanai, M.; Fukuyama, T.; J Antibiot. 2018, $71,240$.

33. Bu'Lock, J. D.; Harley-Mason, J.; J. Chem. Soc. 1951, 2248. 